\title{
High-resolution study of oscillator strengths and predissociation rates for ${ }^{13} \mathrm{C}^{16} \mathrm{O}$ and ${ }^{12} \mathrm{C}^{18} \mathrm{O}$
}

\section{$W-X$ bands and Rydberg complexes in the $92.5-97.5 \mathrm{~nm}$ range}

\author{
M. Eidelsberg ${ }^{1}$, J. L. Lemaire ${ }^{1}$, S. R. Federman ${ }^{2}$, G. Stark ${ }^{3}$, A. N. Heays ${ }^{4}$, L. Gavilan ${ }^{1}$, J. R. Lyons ${ }^{5}$, P. L. Smith ${ }^{6}$, \\ N. de Oliveira ${ }^{7}$, and D. Joyeux ${ }^{7}$ \\ ${ }^{1}$ Observatoire de Paris, LERMA, UMR 8112 du CNRS, 92195 Meudon, France \\ e-mail: [michele.eidelsberg; jean-louis.lemaire]@obspm.fr, lisseth.gavilan@ias.u-psud.fr \\ 2 Department of Physics and Astronomy. University of Toledo, Toledo, OH, USA \\ e-mail: steven.federman@utoledo.edu \\ 3 Department of Physics, Wellesley College, Wellesley, MA, USA \\ e-mail: gstark@wellesley.edu \\ ${ }^{4}$ Leiden Observatory \& Leiden University, PO Box 9513, 2300RA Leiden, The Netherlands \\ e-mail: aheays@strw.leidenuniv.nl \\ 5 School of Earth and Space Exploration, Arizona State University, USA \\ e-mail: jrlyons2@asu.edu \\ 693 Pleasant Street, Watertown MA 02472, USA \\ e-mail: plsmith44@gmail.com \\ 7 DESIRS beam line, Synchrotron SOLEIL, 91192 Gif-sur-Yvette Cedex Saint Aubin, France \\ e-mail: nelson.de.oliveira@synchrotron-soleil.fr, denis.djoyeux@orange.fr
}

Received 17 January 2014 / Accepted 19 March 2014

\begin{abstract}
Models of astronomical environments containing CO require accurate molecular data to reproduce and interpret observations. We conduct experiments at the SOLEIL synchrotron facility to acquire data to model CO photochemistry in the vacuum ultraviolet. The improvement in UV spectroscopic instrumentation in both sensitivity and resolution provides more accurate laboratory spectroscopic determinations. We continue our work on photoabsorption oscillator strengths and predissociation rates for ${ }^{12} \mathrm{C}^{16} \mathrm{O}$; we report new measurements for two additional isotopologues, ${ }^{13} \mathrm{C}^{16} \mathrm{O}$ and ${ }^{12} \mathrm{C}^{18} \mathrm{O}$, of four bands from $X^{1} \Sigma^{+}\left(\mathrm{v}^{\prime \prime}=0\right)$ to the $\mathrm{v}^{\prime}=0-3$ vibrational levels of the core-excited $W^{1} \Pi$ Rydberg state and for four overlapping bands (three resolved and one diffuse) between 92.97 and $93.35 \mathrm{~nm}$. Some of the latter include unidentified perturbations. Absorption spectra were recorded using the vacuum-ultraviolet Fourier-transform spectrometer that is installed on the DESIRS beamline at SOLEIL which provides a resolving power $R=350000$. This resolution allows the analysis of individual line strengths and widths in the electronic transitions and the identification of a previously unobserved perturbation in the W(1) level. Gas column densities in the differentially-pumped system were calibrated using the $B{ }^{1} \Sigma^{+}-X^{1} \Sigma^{+}\left(\mathrm{v}^{\prime}=0, \mathrm{v}^{\prime \prime}=0\right)$ band. Absorption bands are analyzed by synthesizing line and band profiles and fitting them to the measured spectra. These considerably improved results are compared with earlier determinations.
\end{abstract}

Key words. ISM: molecules - methods: laboratory: molecular - techniques: spectroscopic - ultraviolet: ISM

\section{Introduction}

Owing to its high abundance, $\mathrm{CO}$ is used as a probe of many astronomical environments, including photon-dominated regions in interstellar clouds, circumstellar disks around newly formed stars, and the envelopes surrounding stars near the end of their lives. In these environments, the carbon monoxide abundance and the ratio of its isotopologues are determined by its photochemistry under ultraviolet irradiation.

Building upon the publication of results concerning ${ }^{12} \mathrm{C}^{16} \mathrm{O}$ (Eidelsberg et al. 2012, hereafter E12), the current investigation describes our high-resolution measurements of two additional $\mathrm{CO}$ isotopologues, ${ }^{13} \mathrm{C}^{16} \mathrm{O}$ and ${ }^{12} \mathrm{C}^{18} \mathrm{O}$. This work is part of a larger effort to catalog, interpret, and model the photoabsorption spectrum of CO throughout the 91 to $112 \mathrm{~nm}$ region. We present oscillator strengths ( $f$-values) and upper-level predissociation rates for transitions to the four lowest vibrational levels of the $W 3 \mathrm{~s} \sigma{ }^{1} \Pi$ state (built on the $\mathrm{CO}^{+} A^{2} \Pi$ core) and two $\mathrm{p}$ complexes, $4 \mathrm{p}(2)$ and $5 \mathrm{p}(0)$, in the Rydberg series that converge to the $\mathrm{v}=2$ and $\mathrm{v}=0$ levels of the $\mathrm{CO}^{+}$ground state (Eidelsberg et al. 2004a).

Our measurements were undertaken at the third-generation SOLEIL synchrotron facility in Saint-Aubin, France. The vacuum-ultraviolet Fourier-transform spectrometer (VUV-FTS) installed on the DESIRS beam line, which combines high spectral resolution and high signal-to-noise, has allowed us to improve upon our earlier results for the $W-X$ bands and the $4 p$ and $5 \mathrm{p}$ complexes of ${ }^{13} \mathrm{C}^{16} \mathrm{O}$ and ${ }^{12} \mathrm{C}^{18} \mathrm{O}$ (Eidelsberg et al. 1991, 2006).

The VUV-FTS spectra provide the most detailed view of the $W-X$ bands and $4 \mathrm{p} 5 \mathrm{p}$ complexes for ${ }^{13} \mathrm{C}^{16} \mathrm{O}$ and ${ }^{12} \mathrm{C}^{18} \mathrm{O}$ to date. In the course of our analyses, we find (1) differences in $f$-values 
and predissociation rates for levels of $e$ - and $f$-parity for several bands; (2) perturbations not observed before; and (3) regular sequences of lines from unidentified bands. Here, we discuss these findings and focus on the refined values for $f$-values and predissociation rates. In future publications, we will place the results into context from the perspective of molecular structure.

This paper is organized in the following way. Section 2 describes the experiment setup, while Sect. 3 gives an outline of the analysis. The next Sect. 4 presents our results for the $W-X$ bands (Sect. 4.1) and the 4p5p complexes (Sect. 4.2). The last section places these results into an astrophysical context.

\section{Experimental setup}

The experimental setup, the VUV-FTS end-station of the highresolution absorption spectroscopy branch of the DESIRS beamline at the SOLEIL Synchrotron, is described in several publications (de Oliveira et al. 2009, 2011; Nahon et al. 2012, 2013) in detail. An extended description of its specific use for $\mathrm{CO}$ measurements is presented in E12 and in Gavilan et al. (2013). Here, we only summarize the main features.

The undulator source (with a Gaussian-like profile of typical bandwidth of $\sim 7 \mathrm{~nm}$ at $100 \mathrm{~nm}$ ) delivers an harmonic-free coherent continuum background after passing through a gas filter filled with argon. Two overlapping spectral windows were employed in the present measurements (not including the window centered on the $B(0)-X(0)$ calibration band at $112 \mathrm{~nm}$ ).

The gas-sample chamber includes a windowless gas cell (10-cm long that is equipped with two $15-\mathrm{cm}$ external capillaries and permanently installed) that can be cooled with liquid nitrogen (contained in a concentric cylindrical vessel). High-purity gases ${ }^{13} \mathrm{C}^{16} \mathrm{O}$ (Messer $\left({ }^{13} \mathrm{C}\right.$ : $99.1 \% ;{ }^{16} \mathrm{O} 99.95 \%$ ) or $\mathrm{CK}$-gas $\left({ }^{13} \mathrm{C} 99 \% ;{ }^{18} \mathrm{O}<2 \%\right)$ ), and ${ }^{12} \mathrm{C}^{18} \mathrm{O}$ (ICON isotopes, ${ }^{18} \mathrm{O} 99 \%$ ) continuously flow through the open cell.

Two stages of differential pumping maintain the ultrahigh vacuum in the VUV-FTS and in the DESIRS beamline. The pressure in the absorption cell cannot be directly measured nor is its pressure constant with position in the cell and capillaries. A 0.1 mbar full-scale capacitance gauge monitored the CO pressure in the external gas-handling system. Small drifts in this pressure $(\sim 5 \%)$ were electronically recorded during absorption scans. The CO column densities in the windowless cell were determined for each external pressure setting by recording a series of absorption profiles of the $B\left(\mathrm{v}^{\prime}=0\right)-X\left(\mathrm{v}^{\prime \prime}=0\right)$ band (labeled $\mathrm{B} 00$ for brevity) at $112 \mathrm{~nm}$. The B00 band $f$-value of ${ }^{12} \mathrm{C}^{16} \mathrm{O}$ has been well-characterized via laser-based and synchrotron-based absorption measurements in a windowed cell (Stark et al. 1999 and Federman et al. 2001, respectively). Pressure values usually ranged from 3 to $60 \mu$ bar (recorded upstream from the windowless cell), providing the cell with column densities in the range of 6 to $120 \times 10^{14} \mathrm{~cm}^{-2}$. To avoid saturation effects in the strongest bands, only pressures providing column densities in the 3 to $15 \times 10^{14} \mathrm{~cm}^{-2}$ range have been used in the fitting procedure, which correspond to an optical depth $<1.6$ for the thickest lines of the B00 calibration band. When necessary, spectra obtained with the liquid-nitrogen cooled windowless cell were recorded at lower pressures to disentangle the regions where the lines are congested, as in band heads, and where bands overlap. In a few cases, higher pressures up to 3 mbar were used to detect faint lines in the blue and red wings of some bands.

Owing to strict linearity in the wavenumber scale, the spectra can be put on an absolute scale using a single reference wavelength in the source. The presence of a strong Ar I line at $111818.05 \mathrm{~cm}^{-1}$, compiled in the NIST Atomic Database
(Saloman 2004), is used to improve the accuracy in the wavelength calibration by setting all the scans on the same wavelength scale before co-addition.

In summary, the VUV-FTS provides a typical measured resolving power of $\sim 350000$ in the 90 to $125 \mathrm{~nm}$ range, which is considerably higher than conventional broadband techniques based on grating spectrometers. Furthermore, the instrument provides an efficient data collection rate (de Oliveira et al. 2011), which is particularly important during a synchrotron run because the time given to perform measurements is limited. The quality of the $\mathrm{CO}$ absorption spectra obtained with this instrument shows significant improvement over those previously obtained at the Super-ACO synchrotron ring in Orsay (Eidelsberg et al. 2004b, 2006) and at the Photon Factory facility in Japan (e.g., Stark et al. 1991, 1993). The detailed analyses presented below are a consequence of this improvement.

\section{Data analysis}

The fitting procedure used to determine $f$-values of absorption bands in the two isotopic species ${ }^{13} \mathrm{C}^{16} \mathrm{O}$ and ${ }^{12} \mathrm{C}^{18} \mathrm{O}$ has been previously described (Eidelsberg et al. 1999, 2004b) and recently applied to the absorption spectra of ${ }^{12} \mathrm{C}^{16} \mathrm{O}$ that is obtained with the VUV-FTS at SOLEIL (E12) under the same experimental conditions as used in the present study. Here, we provide a brief summary. From the record of the transmitted intensity, $I(\lambda)$, we first derive the incident flux of the undulator source, $I_{0}(\lambda)$. This is obtained either by a linear interpolation over a small wavelength range (in the case of the $W-X$ bands) or by a curve-fitting interpolation of $I_{0}(\lambda)$ from wavelength regions adjacent to the absorption features that are free of absorption (in the case of the $4 \mathrm{p} 5 \mathrm{p}$ complexes). For an ideal measurement with infinite resolving power, $I(\lambda)$ and $I_{0}(\lambda)$ may be transformed into an optical depth, $\tau(\lambda)$, using the Beer Lambert law,

$\tau(\lambda)=\ln \left[I_{0}(\lambda) / I(\lambda)\right]$

The absorption cross section, $\sigma(\lambda)$, and the band oscillator strength, $f_{\mathrm{v}^{\prime} \mathrm{v}^{\prime \prime}}$, is related to the optical depth and gas column density, $N$, according to $\sigma(\lambda)=\tau(\lambda) / N$, and

$f_{\mathrm{v}^{\prime} \mathrm{v}^{\prime \prime}}=\left(1.13 \times 10^{18}\right) \frac{\int \tau(\lambda) \mathrm{d} \lambda}{N \lambda^{2}}$,

where $\lambda$ is in $\mathrm{nm}, N$ is the column density in $\mathrm{cm}^{-2}, \sigma$ is in $\mathrm{cm}^{2}$, and the integration is over the band profile. For our measurements, the lower level $\mathrm{v}^{\prime \prime}$ always refers to the $X^{1} \Sigma^{+}\left(\mathrm{v}^{\prime \prime}=0\right)$ ground state level.

To take the effects of instrumental broadening into account, a simulated absorption spectrum is calculated for each band from the wavelength, the line strength, and the predissociation linewidth of each constituent rotational line. Then Doppler broadened line-shapes are constructed for each line, and their sum is used to generate an optical depth and ideal absorption spectrum, $I(\lambda)$. A model transmission spectrum is obtained by convolving $I(\lambda)$ with a sinc-function instrumental broadening profile that matches the theoretical profile of the Fourier transform spectrometer. The profile reproduces the oscillations seen for the narrow atomic Ar absorption lines that are used for wavelength calibration in our experiments (as in Gavilan et al. 2013) in detail. The full width at half maximum (FWHM) of the instrumental sinc function is $4.2 \times 10^{-4} \mathrm{~nm}$ at $115 \mathrm{~nm}$ and $2.8 \times$ $10^{-4} \mathrm{~nm}$ at $93.1 \mathrm{~nm}$. 
The wavelengths of rotational lines within the studied bands were fixed to previously published values, when available (for ${ }^{13} \mathrm{C}^{16} \mathrm{O}$, Eikema et al. 1994; for ${ }^{13} \mathrm{C}^{16} \mathrm{O}$ and ${ }^{12} \mathrm{C}^{18} \mathrm{O}$ adjusted to match the measured SOLEIL spectra. The simulated spectrum is adjusted in addition to best match the measured spectra by iterative individual fitting or by a non-linear least square fitting procedure in which the band oscillator strengths and the predissociation linewidths are free parameters. For some measured bands in this study, the rotational line $f$-values follow the simple patterns associated with unperturbed transitions and a temperature dependent Boltzmann distribution of the ground state rotational levels. For unperturbed ${ }^{1} \Sigma-{ }^{1} \Sigma$ and ${ }^{1} \Pi-{ }^{1} \Sigma$ transitions, the band $f_{\mathrm{v}^{\prime} \mathrm{v}^{\prime \prime}}$ oscillator strength is related to the rotational line oscillator strength $f_{\mathrm{v}^{\prime} \mathrm{v}^{\prime \prime} J^{\prime} J^{\prime \prime}}$ by

$f_{\mathrm{v}^{\prime} \mathrm{v}^{\prime \prime} J^{\prime} J^{\prime \prime}}=f_{\mathrm{v}^{\prime} \mathrm{v}^{\prime \prime}} /\left(2 J^{\prime \prime}+1\right) \times S_{J^{\prime} J^{\prime \prime}}$,

where $S_{J^{\prime} J^{\prime \prime}}$ are the Hönl-London strength factors (Herzberg 1950). Hönl-London factors for a ${ }^{1} \Sigma-{ }^{1} \Sigma$ transition are $J^{\prime \prime}$ and $\left(J^{\prime \prime}+1\right)$ for the P- and R-branch, respectively, while they are $J^{\prime \prime}-1,2 J^{\prime \prime}+1$, and $J^{\prime \prime}+2$ for the P-, Q-, and R-branch for a ${ }^{1} \Pi-{ }^{1} \Sigma$ transition, respectively.

For unperturbed bands, the band $f$-values derived from the application of Eq. (3) to measured line $f$-values are independent of the rotational quantum number $J$, and a single band oscillator strength is calculated by the fitting procedure described above for an absorption band.

In a few cases, the line $f$-value patterns deviate significantly from those predicted by Hönl-London factors for the R-, P-, and Q-branches, and the band $f$-value, which can be determined from fitting of the well-resolved rotational lines, is characterized by a marked $J$ dependence. The derived band $f\left(J^{\prime}\right)$ values are then treated as a polynomial in $J^{\prime}\left(J^{\prime}+1\right)$ that is extrapolated to $J^{\prime}=0$ and referred to as a rotationless band $f$-value. They are noted below as $f(0)$ and $f(x)$, so that $f\left(J^{\prime}\right)=f(0)+f(x)$ with $x=$ $J^{\prime}\left(J^{\prime}+1\right)$.

Most of the bands display a $J$ dependence in their linewidths and/or different linewidths associated with transitions to the $e$ and $f$-parity levels of the upper state. The $J$ dependences of these linewidths are also represented by simple polynomial fits in $J^{\prime}\left(J^{\prime}+1\right)$. For the $W$ bands with $v^{\prime}=2$, an additional quadratic term was needed for both isotopologues.

For diffuse bands, an integration of $\sigma(\lambda)$ over their full extent is required. For the few unidentified lines observed within a wellknown band, determination of an approximate $f$-value for this set of lines was obtained by subtracting the $f$-value of the known band, as obtained by fitting, from the $f$-value derived from the experimental spectrum.

A weighted average of nearly identical results for the $B(0)$ - $X(0)$ absolute band $f$-value $\left(6.5 \times 10^{-3}\right)$ was used for pressure calibration. The weighted uncertainty is $7 \%$. This band was regularly recorded to calibrate the absolute column density of bands observed for the ${ }^{13} \mathrm{C}^{16} \mathrm{O}$ and ${ }^{12} \mathrm{C}^{18} \mathrm{O}$ isotopologues. An isotopologue independence for this band is assumed, as discussed in more detail in the paper on the $B-X, C-X$, and $E-X$ bands for five isotopologues of CO (Stark et al. 2014).

From the measured natural (Lorentzian) linewidths, $\Gamma_{L}$, of rotational transitions, predissociation rates $k\left(\mathrm{~s}^{-1}\right)=2 \pi c \Gamma_{L}$ are calculated from the relation (Eidelsberg et al. 2006),

$$
k=\left(1.884 \times 10^{15}\right) \Gamma_{L}(\mathrm{pm})[\lambda(\mathrm{nm})]^{-2}
$$

or

$k=\left(1.884 \times 10^{11}\right) \Gamma_{L}\left(\mathrm{~cm}^{-1}\right)$, where $\Gamma_{L}$ is measured at FWHM and $\lambda$ is the wavelength of the band origin for the transition.

The uncertainties in the tables below were derived in the following manner. For $f$-values, several steps were involved. When results for more than one pressure were used, a weighted average was obtained from the individual results, where the uncertainties in the fit were adopted as weights. The uncertainties in the $f$-value for the calibration band $(7 \%)$ and in systematic effects that are inferred from the range of values obtained at different pressures (typically 1-2\%) were added in quadrature to the uncertainty that is associated with the weighted average used to arrive at the uncertainties appearing on the tables. For predissociation rates, the uncertainties from the least-squares fit were used in a weighted average. The resulting uncertainty appears in the tables. The results obtained at $293 \mathrm{~K}$ and $77 \mathrm{~K}$ are consistent, which do not show any significant difference in the predissociation linewidths. The consistency of the $J^{\prime}$ dependence is more difficult to evaluate as the number of available lines at $77 \mathrm{~K}$ is heavily reduced $\left(J^{\prime} \leq 5\right)$, and their intensities are much more reduced at high $J^{\prime}$.

\section{Results and discussion}

\section{1. $W$ bands}

The $3 \mathrm{~s} \sigma^{1} \Pi$ state (W state) is the $n=3$ member of the Rydberg series that converges to the $\mathrm{A}^{2} \Pi$ second ionization limit of $\mathrm{CO}^{+}$. The four absorption bands $W\left(\mathrm{v}^{\prime}=0,1,2,3\right)-X^{1} \Sigma^{+}\left(\mathrm{v}^{\prime \prime}=0\right)$ of CO (labeled W00, W10, W20, and W30 for brevity) were previously studied at a lower resolution for the two isotopologues, ${ }^{13} \mathrm{C}^{16} \mathrm{O}$ and ${ }^{12} \mathrm{C}^{18} \mathrm{O}$ (Eidelsberg et al. 2006). As for the recent re-investigation of these bands in ${ }^{12} \mathrm{C}^{16} \mathrm{O}(\mathrm{E} 12)$, the improvement in resolution allows us to distinguish many new rotational lines, for which wavelengths have been measured. The measured wavelengths of the rotationally resolved lines of W00 and $\mathrm{W} 20$ in ${ }^{13} \mathrm{C}^{16} \mathrm{O}$ are in very good agreement with the published data of Eikema et al. (1994). A new set of wavelengths for the W00 and $\mathrm{W} 10$ bands in ${ }^{13} \mathrm{C}^{16} \mathrm{O}$ and ${ }^{12} \mathrm{C}^{18} \mathrm{O}$ have been determined from our SOLEIL spectra and have been recently published (Lefèbvre-Brion \& Eidelsberg 2012). The newly observed perturbations in the W10 and W20 bands of our ${ }^{12} \mathrm{C}^{16} \mathrm{O}$ spectra are also observed in these two isotopologues, which result in a new assignment of the rotational lines.

For all four $W-X$ bands, a single band $f$-value is specified; the strengths of individual rotational transitions are well described by the Hönl-London line strength factors $\left(S_{J^{\prime} J^{\prime \prime}}\right)$ and a temperature dependent $(293 \mathrm{~K})$ Boltzmann distribution of ground-state rotational levels. The spectra for both isotopologues ${ }^{13} \mathrm{C}^{16} \mathrm{O}$ and ${ }^{12} \mathrm{C}^{18} \mathrm{O}$ are qualitatively very similar and follow the same trend of oscillator strengths and predissociation rates for increasing $\mathrm{v}^{\prime}$.

\subsection{1. $W-X(0,0)$}

The Q lines of the W00 band are well resolved until $J^{\prime}=22$, whereas only $\mathrm{P}$ lines from $J^{\prime}=5$ to 16 are resolved and most $\mathrm{R}$ lines overlap (see Fig. 1 for ${ }^{13} \mathrm{C}^{16} \mathrm{O}$ and Fig. 2 for ${ }^{12} \mathrm{C}^{18} \mathrm{O}$ ).

Band oscillator strengths derived from fitting of individual Q-branch lines were found to decrease slightly from $J^{\prime}>10$ for both ${ }^{13} \mathrm{C}^{16} \mathrm{O}$ (Fig. 3) and ${ }^{12} \mathrm{C}^{18} \mathrm{O}$ (Fig. 4). The resolved P-lines exhibit a sharp drop in intensity and distinct line broadening. A single band oscillator strength is obtained by fitting simultaneously the R-, P-, and Q-branch lines using Hönl-London factors 


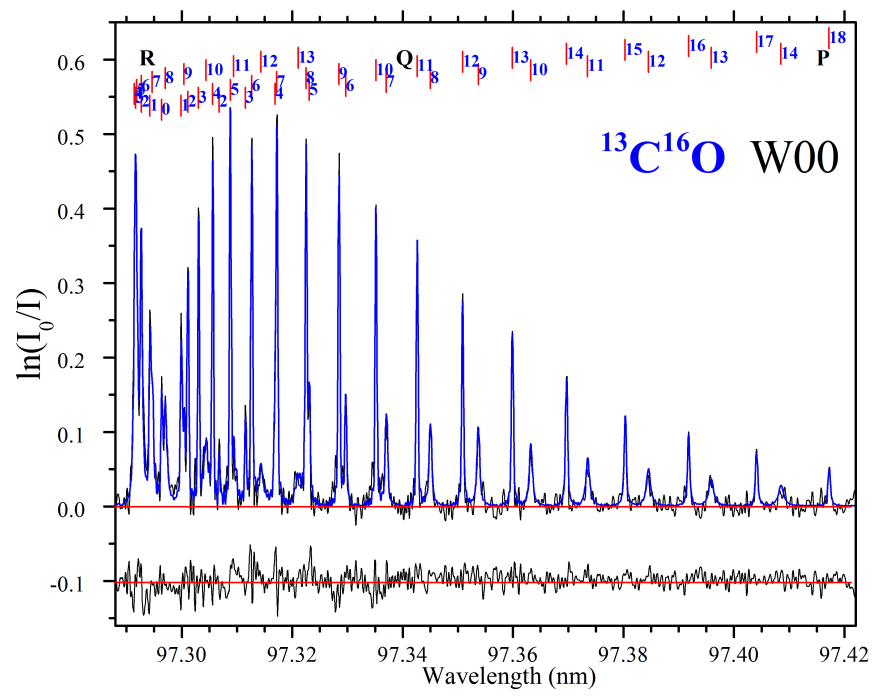

Fig. 1. ${ }^{13} \mathrm{C}^{16} \mathrm{O} W\left(\mathrm{v}^{\prime}=0\right)-X\left(\mathrm{v}^{\prime \prime}=0\right)$ band. Experimental spectrum (black line) and fit (blue line). The fitting residuals are shifted by -0.1 .

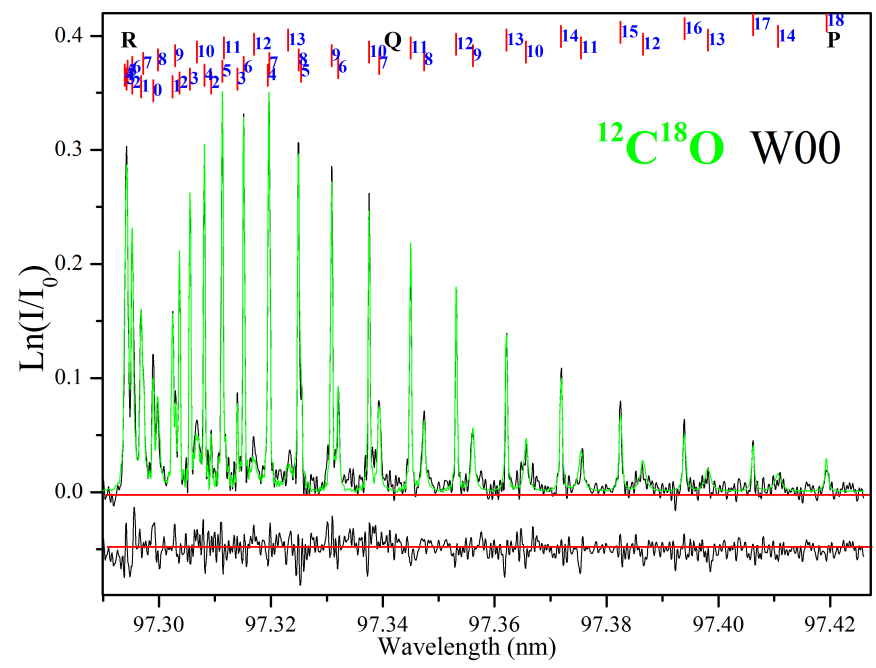

Fig. 2. ${ }^{12} \mathrm{C}^{18} \mathrm{O} W\left(\mathrm{v}^{\prime}=0\right)-X\left(\mathrm{v}^{\prime \prime}=0\right)$ band. Experimental spectrum (black line) and fit (green line). The fitting residuals are shifted by -0.05 .

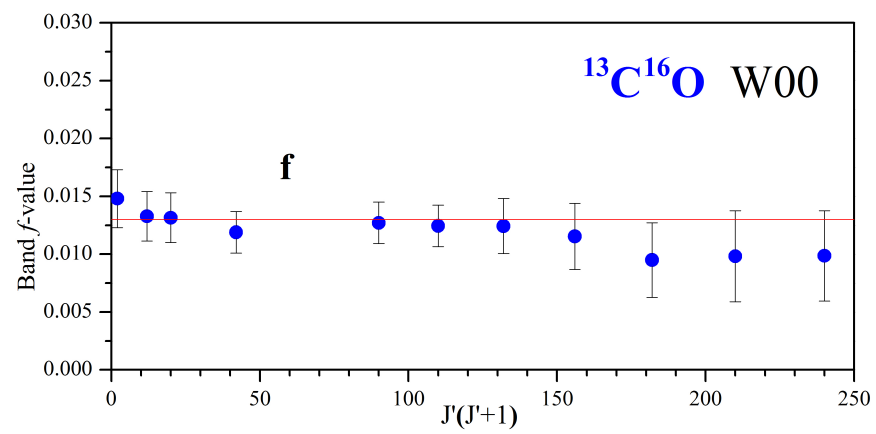

Fig. 3. ${ }^{13} \mathrm{C}^{16} \mathrm{O}$ oscillator strengths for the $W\left(\mathrm{v}^{\prime}=0\right)-X\left(\mathrm{v}^{\prime \prime}=0\right)$ band, as deduced from the Q-branch analysis only (see text).

with a small correction $(<2 \%)$ in intensity for $\mathrm{P}, \mathrm{R}$, and $\mathrm{Q}$ lines of high $J^{\prime}$. These intensity corrections with their error bars are included in Figs. 3 and 4). However, due to the large error bars at high $J^{\prime}$, a single oscillator strength is quoted in Tables 1 and 2.

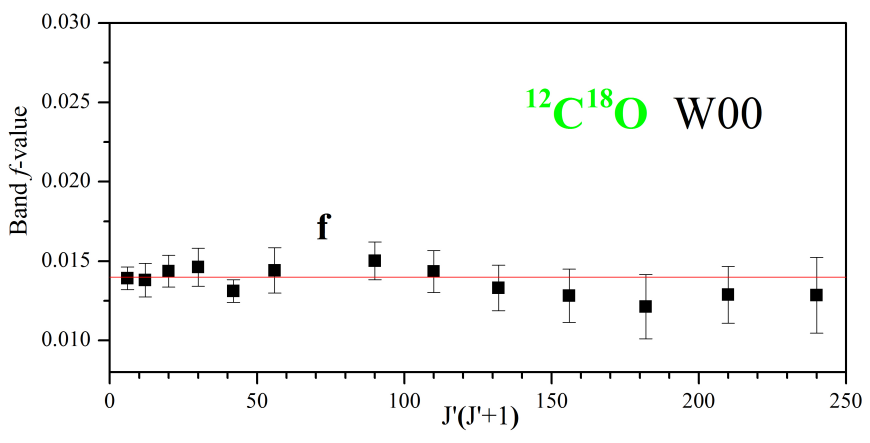

Fig. 4. ${ }^{12} \mathrm{C}^{18} \mathrm{O}$ oscillator strengths for the $W\left(\mathrm{v}^{\prime}=0\right)-X\left(\mathrm{v}^{\prime \prime}=0\right)$ band, as deduced from the Q-branch analysis only (see text).

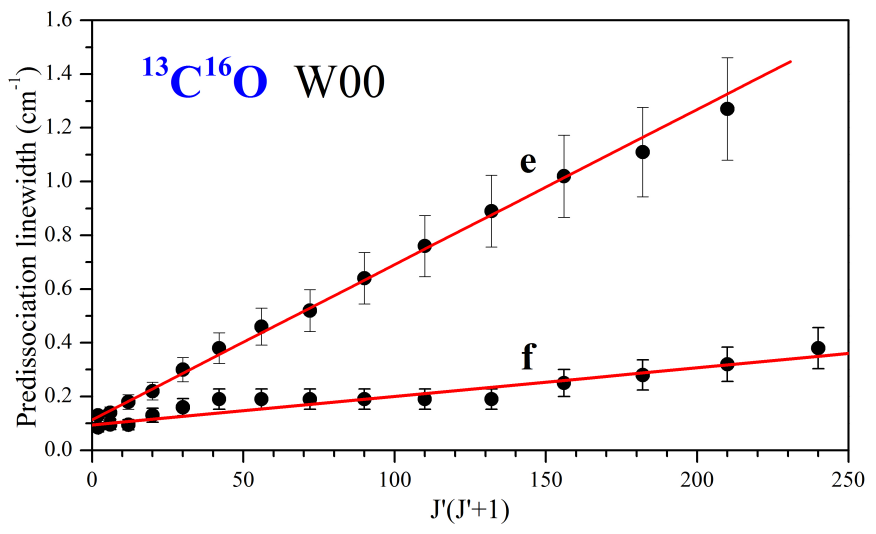

Fig. 5. ${ }^{13} \mathrm{C}^{16} \mathrm{O}$ measured predissociation linewidths for the $W\left(\mathrm{v}^{\prime}=0\right)-$ $X\left(\mathrm{v}^{\prime \prime}=0\right)$.

Table 1. ${ }^{13} \mathrm{C}^{16} \mathrm{O}$ oscillator strengths for the $W(\mathrm{v}=0,1,2,3)-$ $X(0)$ bands.

\begin{tabular}{lcccc}
\hline \hline Ref. & $\mathrm{W}^{a}$ & $\mathrm{~W} 10$ & $\mathrm{~W} 20$ & $\mathrm{~W} 30$ \\
\hline Present & $12.67(0.82)$ & $14.78(0.94)$ & $27.14(1.72)$ & $15.92(1.02)$ \\
E06 & $15.1(0.7)$ & $16.1(2.8)$ & $29.1(1.3)$ & $18.7(1.4)$ \\
E91 & $13.2(1.3)$ & $16.1(1.6)$ & $27.9(2.8)$ & $18.7(1.9)$ \\
\hline
\end{tabular}

Notes. Uncertainties are given in parentheses (1 standard error). Comparison with previous $f$-value results: E91 (Eidelsberg et al. 1991), E06 (Eidelsberg et al. 2006). ${ }^{(a)} W(0)-X(0)$.

Table 2. ${ }^{12} \mathrm{C}^{18} \mathrm{O}$ oscillator strengths for the $W(\mathrm{v}=0,1,2,3)-$ $X(0)$ bands.

\begin{tabular}{lcccc}
\hline \hline Ref. & $\mathrm{W}^{a}$ & $\mathrm{~W} 10$ & $\mathrm{~W} 20$ & $\mathrm{~W} 30$ \\
\hline Present & $13.94(0.86)$ & $13.37(0.83)$ & $26.40(1.63)$ & $18.10(1.12)$ \\
E91 & $13.2(1.3)$ & $16.1(1.6)$ & $27.9(2.8)$ & $18.6(1.9)$ \\
\hline
\end{tabular}

Notes. Uncertainties are given in parentheses (1 standard error). Comparison with previous $f$-value results: E91 (Eidelsberg et al. 1991). (a) $W(0)-X(0)$.

The Lorentzian linewidths, $\Gamma_{L}$, calculated from fitting individual Q-branch lines increase slightly until $J^{\prime}=12$, while the P-branch linewidths show a rapid increase with $J^{\prime}$. The predissociation linewidths were fit to separate functions of the form $\Gamma_{L}=f\left[\left(J^{\prime}\right)\left(J^{\prime}+1\right)\right]$ for $\Pi_{e}$ and $\Pi_{f}$ components that were obtained from the measured linewidths (See Fig. 5 for ${ }^{13} \mathrm{C}^{16} \mathrm{O}$ and Fig. 6 for ${ }^{12} \mathrm{C}^{18} \mathrm{O}$, where both $e$ - and $f$-parity flavors are shown as we are dealing with an upper $\Pi_{e}$ level). For both isotopologues, 


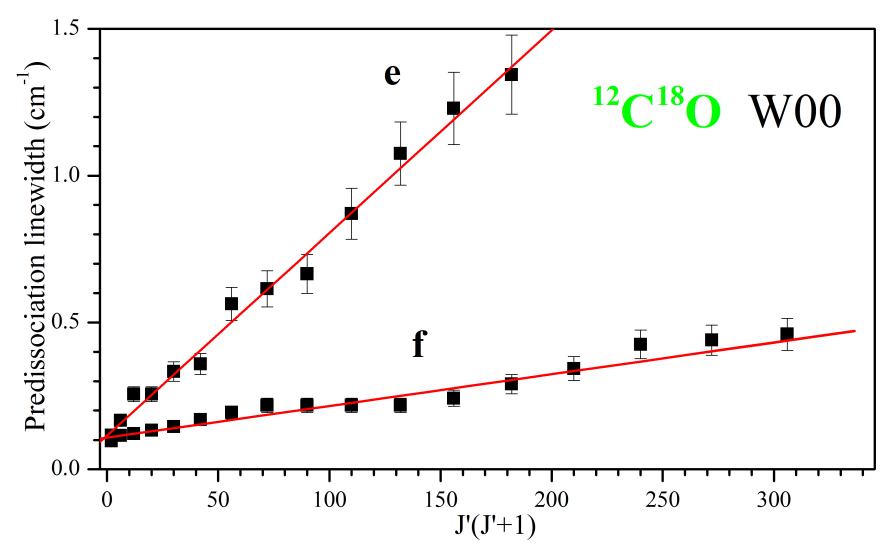

Fig. 6. ${ }^{12} \mathrm{C}^{18} \mathrm{O}$ measured predissociation linewidths for the $W\left(\mathrm{v}^{\prime}=0\right)-$ $X\left(\mathrm{v}^{\prime \prime}=0\right)$ band.

a linear proportionality with $J^{\prime}\left(J^{\prime}+1\right)$ is found for $\Pi_{e}$ components as reported by Eikema et al. (1994) for ${ }^{13} \mathrm{C}^{16} \mathrm{O}$. For the $\Pi_{f}$ components, the predissociation rate slightly increases up to the highest $J$-values. A slight wave-like shape is observed in the predissociation $f$-parity linewidths in Figs. 5 and 6. Such an effect is explained by the difficulty of simultaneously fitting strong Q-lines and weak P-lines when adopting a line by line procedure.

\subsection{2. $W-X(1,0)$}

The W10 band is heavily broadened and has overlapped rotational lines in both the ${ }^{13} \mathrm{C}^{16} \mathrm{O}$ and ${ }^{12} \mathrm{C}^{18} \mathrm{O}$ isotopologues. Thus, few oscillator strengths or widths could be fitted independently. The analysis of this band is complicated by a level crossing between W(1) and another state of lower rotational constant, which occurs between $J^{\prime}=7$ and 8 for both isotopologues. Accompanying this level crossing is rotational linewidth variations, which follow a similar pattern to what was found previously for ${ }^{12} \mathrm{C}^{16} \mathrm{O}$ (E12). That is, the observed widths increase rapidly for low $J^{\prime}$ values until the crossing point with the perturber, after which the observed lines are significantly narrower but continue to broaden. This $J$ dependence was modeled during the fitting of the spectrum as a piecewise linear trend with $J^{\prime}\left(J^{\prime}+1\right)$. Figure 7 shows the $\mathrm{W} 10$ spectrum for ${ }^{13} \mathrm{C}^{16} \mathrm{O}$ (and Fig. 8 for ${ }^{12} \mathrm{C}^{18} \mathrm{O}$ ), where the narrowest lines correspond to $\mathrm{P}(9), \mathrm{Q}(8)$, and $\mathrm{R}(7)$ transitions. The assignment of these distinctive features greatly facilitated the modeling of the rest of the band. The W10 lines that are closest to the crossing point are weakened by the perturbation, and extra lines appear at energies above the band head in high pressure measurements (some of which are noted $\mathbf{p}$ and marked with vertical red lines identifying their exact positions in Figs. 7 and 8). These lines were assigned to the perturbing state; the strongest of these corresponds to the same $J^{\prime}$ as the anomalously weak W10 R-branch lines. For ${ }^{13} \mathrm{C}^{16} \mathrm{O}$, there are five extra $\mathrm{R}$-branch lines and only two for ${ }^{12} \mathrm{C}^{18} \mathrm{O}$. There is some improvement in the fit of the spectrum if extra $\mathrm{P}(6)$ and $\mathrm{Q}(5)$ lines are added to the spectrum of ${ }^{12} \mathrm{C}^{18} \mathrm{O}$. A fit of this band is shown in Fig. 7 for ${ }^{13} \mathrm{C}^{16} \mathrm{O}$ and Fig. 8 for ${ }^{12} \mathrm{C}^{18} \mathrm{O}$.

To study the curious perturbation of W10 in more detail, we have commissioned additional measurements of its FUV absorption, which requires us to employ higher column densities, liquid nitrogen cooled samples, and additional isotopologues of CO. We will present more detailed spectroscopic results for this band in a separate paper (Heays et al., in prep.). The Lorentzian

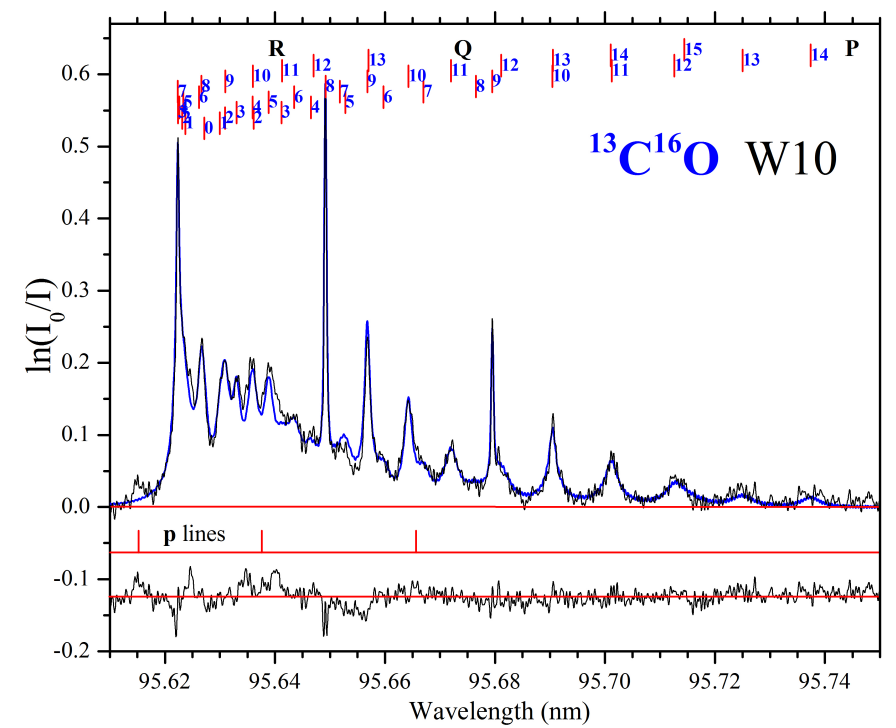

Fig. 7. ${ }^{13} \mathrm{C}^{16} \mathrm{O} W\left(\mathrm{v}^{\prime}=1\right)-X\left(\mathrm{v}^{\prime \prime}=0\right)$ band. Experimental spectrum (black line) and fit (blue line). The fitting residuals are shifted by -0.125 . Perturbing lines, labeled $\mathbf{p}$, are also shown (see text).

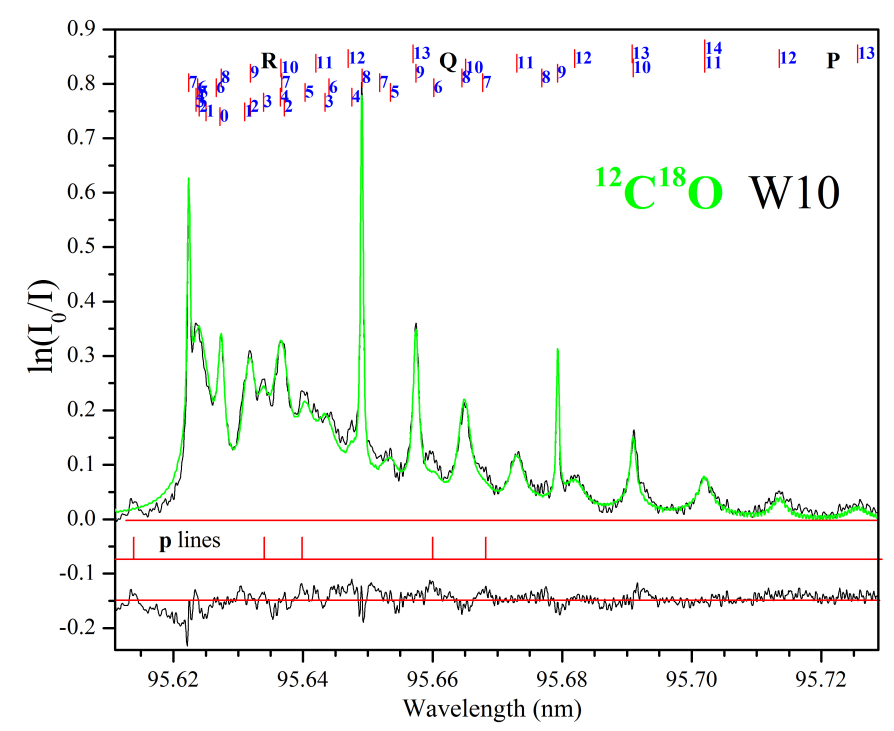

Fig. 8. ${ }^{12} \mathrm{C}^{18} \mathrm{O} W\left(\mathrm{v}^{\prime}=1\right)-X\left(\mathrm{v}^{\prime \prime}=0\right)$ band. Experimental spectrum (black line) and fit (green line). The fitting residuals are shifted by -0.15 . Perturbing lines, labeled $\mathbf{p}$, are also shown (see text).

predissociation linewidths determined for $\mathrm{W} 10$ are shown in Fig. 9 for ${ }^{13} \mathrm{C}^{16} \mathrm{O}$ and Fig. 10 for ${ }^{12} \mathrm{C}^{18} \mathrm{O}$. These clearly show the presence of the perturbation for both isotopologues. The outlying point at $J^{\prime}=7$ for ${ }^{12} \mathrm{C}^{18} \mathrm{O}$ on Fig. 10 could be due either to the heavy blending of the R-lines around $J^{\prime}=6$ and 7 or to a higher-order polynomial dependence, where not enough information is available.

Oscillator strengths measurements similar to the ones shown in Figs. 3 and 4 are not possible for the W10 band, since the P-lines are almost completely blended. The $f$-value is then derived by considering the complete spectrum.

\subsection{3. $W-X(2,0)$}

Rotational line identifications were facilitated by also recording spectra at low temperature, and new line positions were measured for ${ }^{13} \mathrm{C}^{16} \mathrm{O}$ (Fig. 11) and ${ }^{12} \mathrm{C}^{18} \mathrm{O}$ (Fig. 12). 


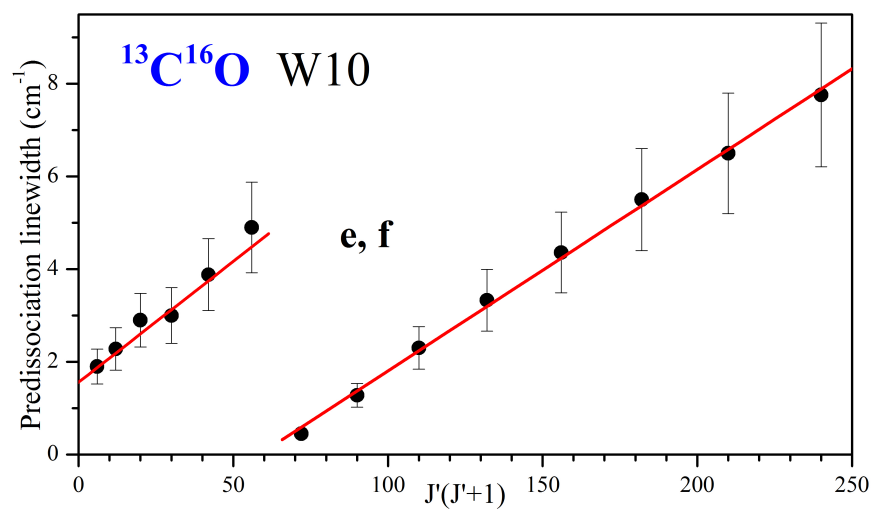

Fig. 9. ${ }^{13} \mathrm{C}^{16} \mathrm{O}$ measured predissociation linewidths for the $W\left(\mathrm{v}^{\prime}=1\right)-$ $X\left(\mathrm{v}^{\prime \prime}=0\right)$ band.

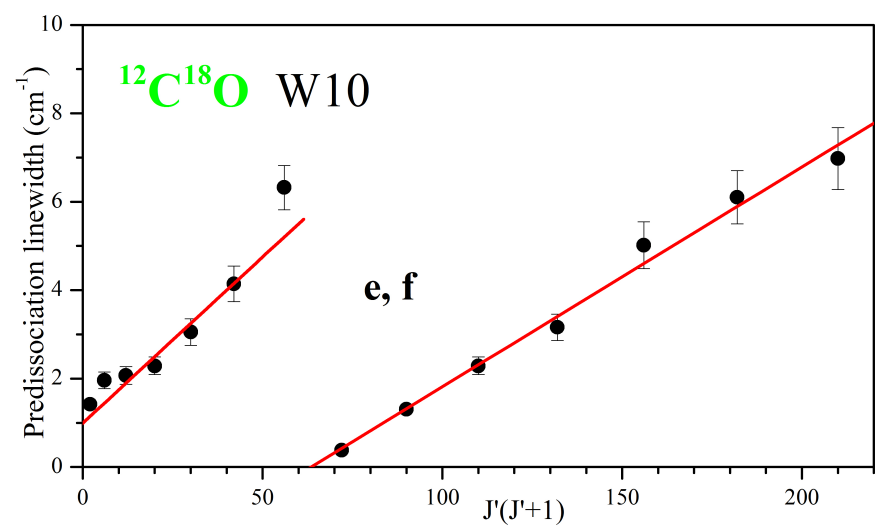

Fig. 10. ${ }^{12} \mathrm{C}^{18} \mathrm{O}$ measured predissociation linewidths for the $W\left(\mathrm{v}^{\prime}=1\right)-$ $X\left(\mathrm{v}^{\prime \prime}=0\right)$ band.

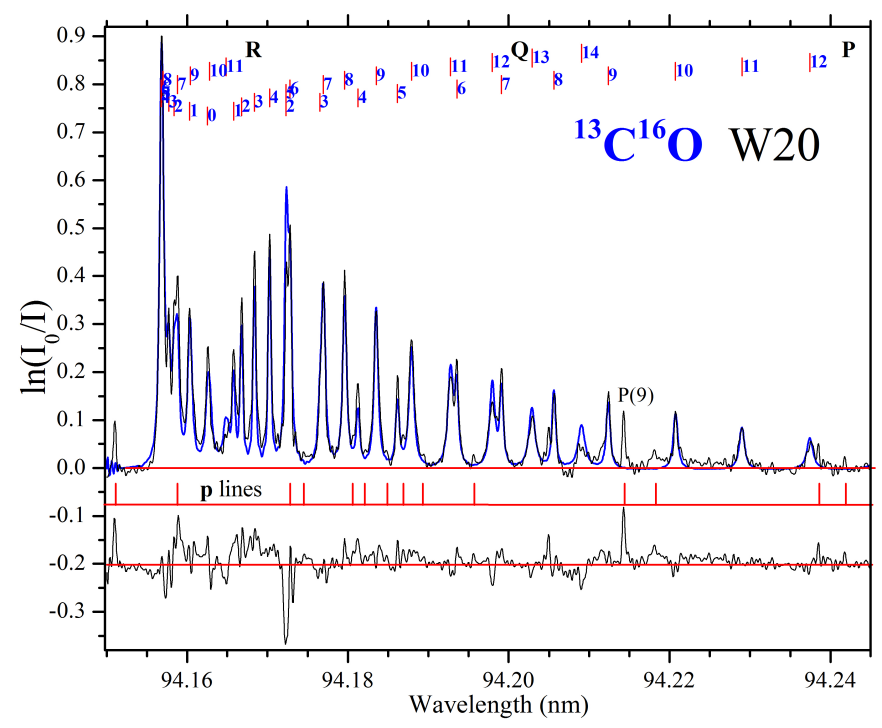

Fig. 11. ${ }^{13} \mathrm{C}^{16} \mathrm{O} W\left(\mathrm{v}^{\prime}=2\right)-X\left(\mathrm{v}^{\prime \prime}=0\right)$ band. Experimental spectrum (black line) and fit (blue line). The fitting residuals are shifted by -0.2. Perturbing or overlapping lines, labeled $\mathbf{p}$, are also shown (see text).

Local perturbations in the observed energies and intensities were found for $\Pi_{e} J=8$ in both isotopologues. A distinct extra feature was observed, assigned as a $\mathrm{P}(9)$ line from the perturbing state, and the quality of the fit of the W20 R-branch bandhead is improved by introducing an additional $\mathrm{R}(7)$ line. In ${ }^{12} \mathrm{C}^{18} \mathrm{O}$, the

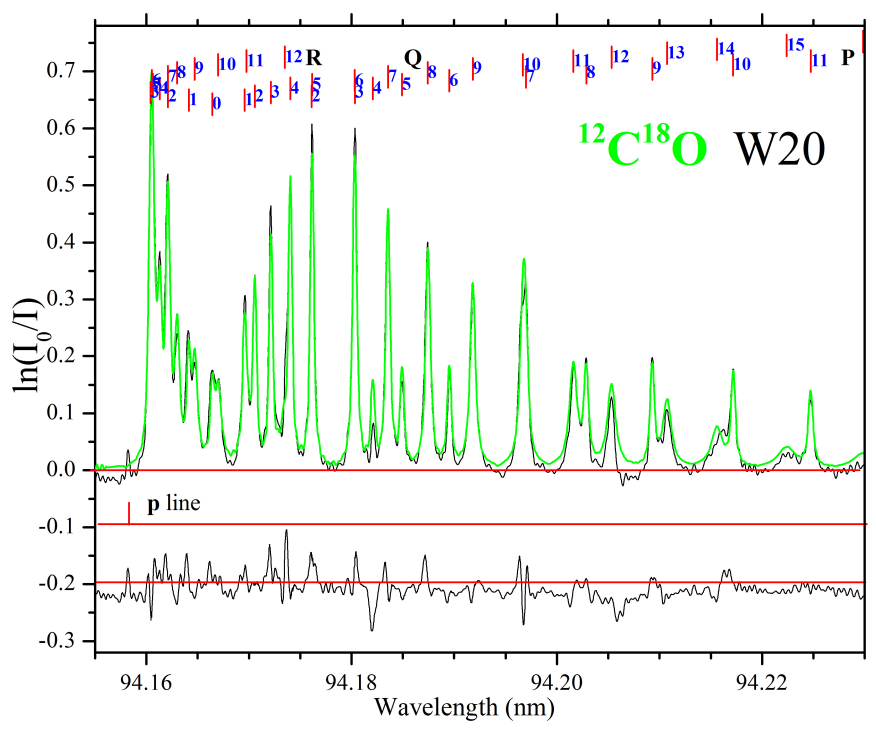

Fig. 12. ${ }^{12} \mathrm{C}^{18} \mathrm{O} W\left(\mathrm{v}^{\prime}=2\right)-X\left(\mathrm{v}^{\prime \prime}=0\right)$ band. Experimental spectrum (black line) and fit (green line). The fitting residuals are shifted by -0.2 . Perturbing lines, labeled $\mathbf{p}$, are also shown (see text).

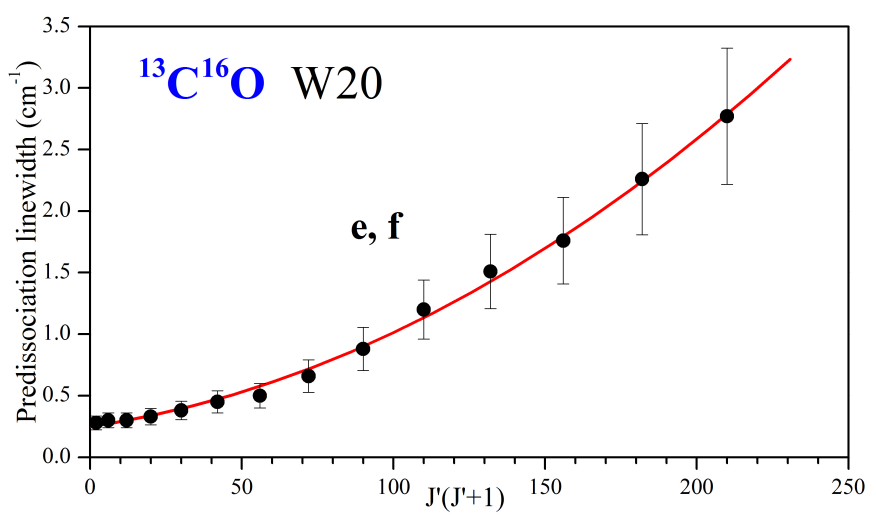

Fig. 13. ${ }^{13} \mathrm{C}^{16} \mathrm{O}$ measured predissociation linewidths for the $W\left(\mathrm{v}^{\prime}=2\right)-$ $X\left(\mathrm{v}^{\prime \prime}=0\right)$ band.

extra $\mathrm{P}(9)$ line is found to be blended with the abnormally strong $\mathrm{Q}(12)$ line observed in our cold spectrum. This perturbation is parity dependent; no corresponding effect is seen for the $\mathrm{Q}(8)$ line. Strength, width, and line position matching this $\mathrm{P}(9)$ line may be explained if the perturber is a bound state of $\Sigma$ symmetry. Other local perturbations of rotational energy levels are found in both isotopologues for $\mathrm{P}(5)$ and $\mathrm{P}(6)$ and shifted by one $J^{\prime}$ value for $\mathrm{Q}(5)$ and $\mathrm{Q}(6)$, and another is found between $\mathrm{Q}(12)$ and $\mathrm{Q}(13)$. New identifications and wavelengths may be obtained by request to the authors. Perturbations are noted $\mathbf{p}$ and marked with vertical red lines identifying their exact positions in Figs. 11 and 12.

The predissociation effect was found to be parity independent, and the line broadening of the R-, P-, and Q-branch lines follows a similar trend. Predissociation rates $\mathrm{k}$ for the $\Pi_{e}$ and $\Pi_{f}$ components were averaged and plotted as a function of $J^{\prime}\left(J^{\prime}+1\right)$ (Fig. 13 for ${ }^{13} \mathrm{C}^{16} \mathrm{O}$ and Fig. 14 for ${ }^{12} \mathrm{C}^{18} \mathrm{O}$ ). They are well represented by a quadratic curve, which reproduces the rapid increase of the predissociation rate from $J^{\prime}=8$, as found by Eikema et al. (1994) for ${ }^{13} \mathrm{C}^{16} \mathrm{O}$.

As for the W10 band, oscillator strength measurements similar to the ones shown in Figs. 3 and 4 are not possible for the 
M. Eidelsberg et al.: High-resolution study of oscillator strengths and predissociation rates for ${ }^{13} \mathrm{C}^{16} \mathrm{O}$ and ${ }^{12} \mathrm{C}^{18} \mathrm{O}$

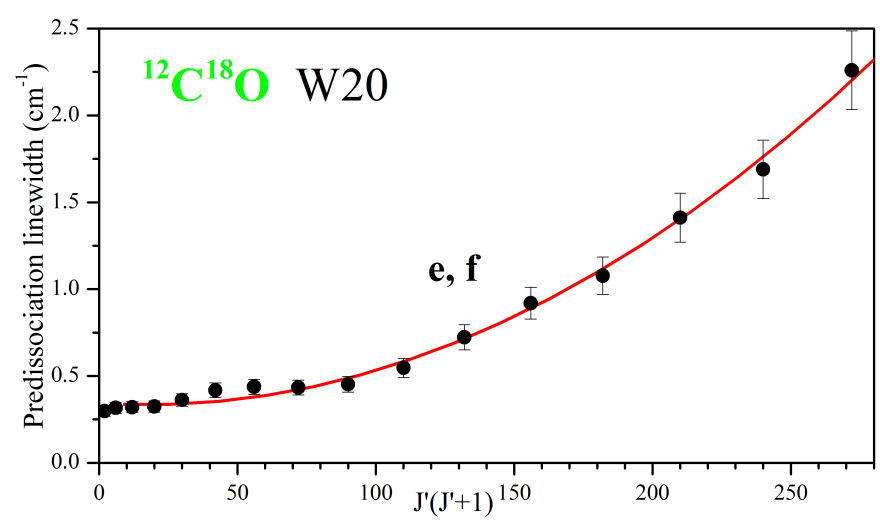

Fig. 14. ${ }^{12} \mathrm{C}^{18} \mathrm{O}$ measured predissociation linewidths for the $W\left(\mathrm{v}^{\prime}=2\right)-$ $X\left(\mathrm{v}^{\prime \prime}=0\right)$ band.

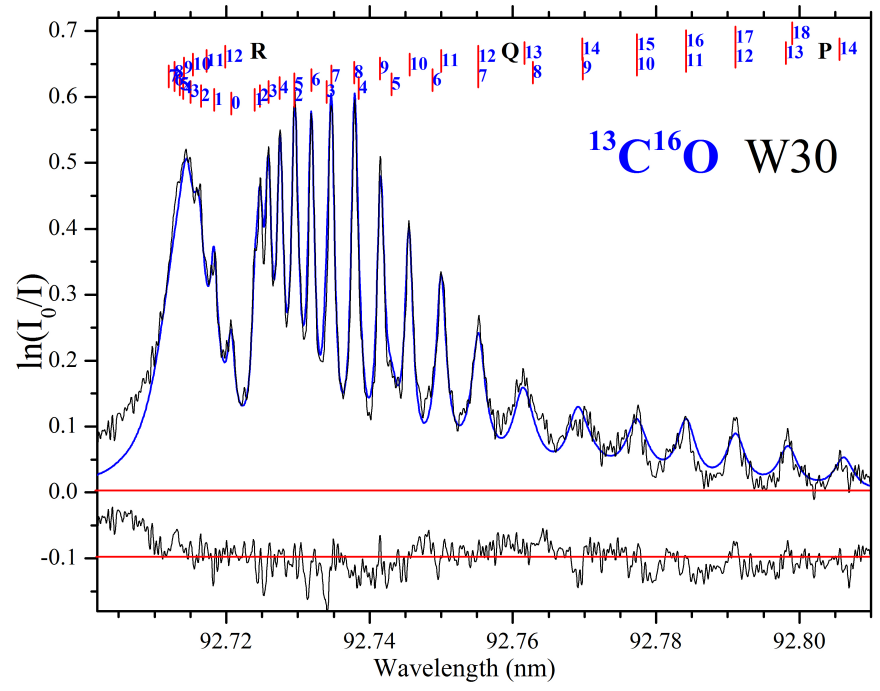

Fig. 15. ${ }^{13} \mathrm{C}^{16} \mathrm{O} W\left(v^{\prime}=3\right)-X\left(\mathrm{v}^{\prime \prime}=0\right)$ band. Experimental spectrum (black line) and fit (blue line). The fitting residuals are shifted by -0.05 .

W20 band as the P- and Q-lines are completely mixed (despite that a few lines at high $J^{\prime}$ are separated). The $f$-value is then derived by considering the complete spectrum.

\subsection{4. $W-X(3,0)$}

The W30 band is very diffuse, but its synthesis, shown in Fig. 15 for ${ }^{13} \mathrm{C}^{16} \mathrm{O}$ and Fig. 16 for ${ }^{12} \mathrm{C}^{18} \mathrm{O}$, was easily achieved: its rotational line strengths are well characterized by Hönl-London factors. Only a few strong Q lines are resolved; all R-branch lines and P-branch lines until $J^{\prime}=7$ are blended, and only a few weak and diffuse $\mathrm{P}$ lines for $J^{\prime}>7$ in ${ }^{13} \mathrm{C}^{16} \mathrm{O}$ and $J^{\prime}>8$ in ${ }^{12} \mathrm{C}^{18} \mathrm{O}$ are independently resolved. In both isotopologues, the predissociation rates were determined by fitting the band with a $J$-independent oscillator strength, and the measured predissociation linewidths were found to be $J$-dependent and distinct for $e$ - and $f$-parity levels. The linear $J$ dependence of predissociation linewidths assumed during the fitting process are plotted in Fig. 17 for ${ }^{13} \mathrm{C}^{16} \mathrm{O}$ and Fig. 18 for ${ }^{12} \mathrm{C}^{18} \mathrm{O}$.

As for the $W 10$ and $W 20$ bands, oscillator strengths measurements similar to the ones shown in Figs. 3 and 4 are not possible for the $W 30$ band, as the P-lines are almost completely blended. The $f$-value is then derived considering the complete spectrum.

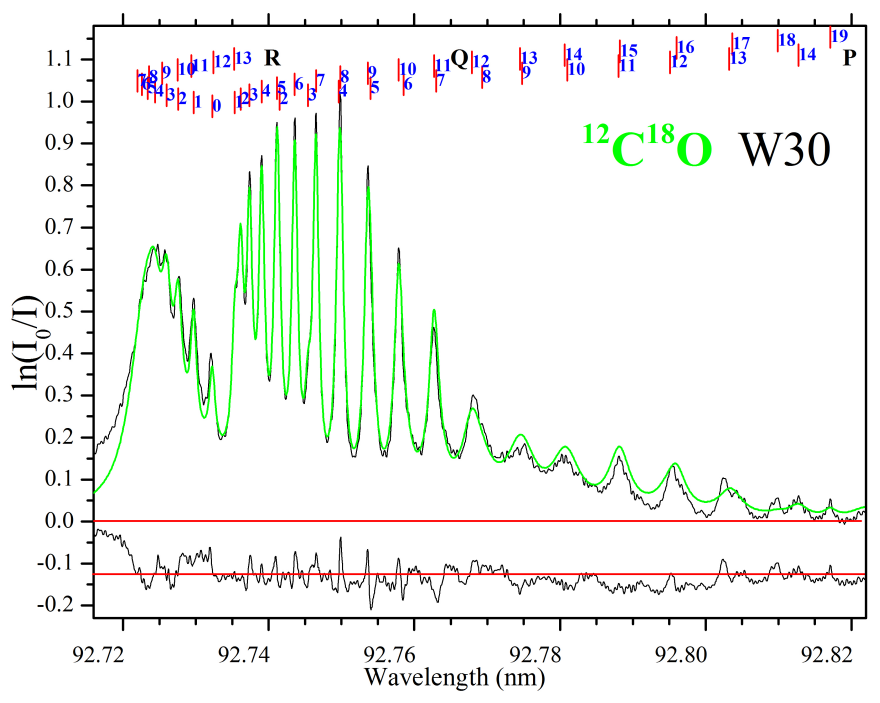

Fig. 16. ${ }^{12} \mathrm{C}^{18} \mathrm{O} W\left(v^{\prime}=3\right)-X\left(\mathrm{v}^{\prime \prime}=0\right)$ band. Experimental spectrum (black line) and fit (green line). The fitting residuals are shifted by -0.15 .

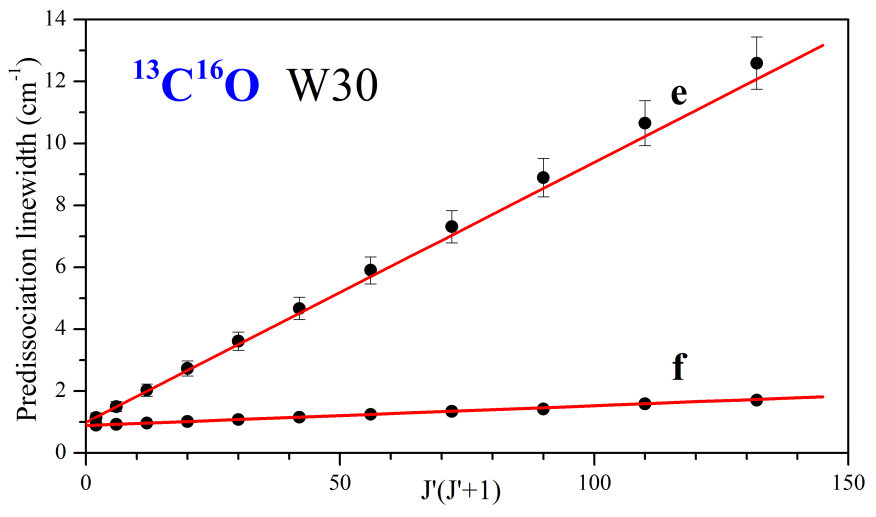

Fig. 17. ${ }^{13} \mathrm{C}^{16} \mathrm{O}$ measured predissociation linewidths for the $W\left(\mathrm{v}^{\prime}=3\right)-$ $X\left(\mathrm{v}^{\prime \prime}=0\right)$ band.

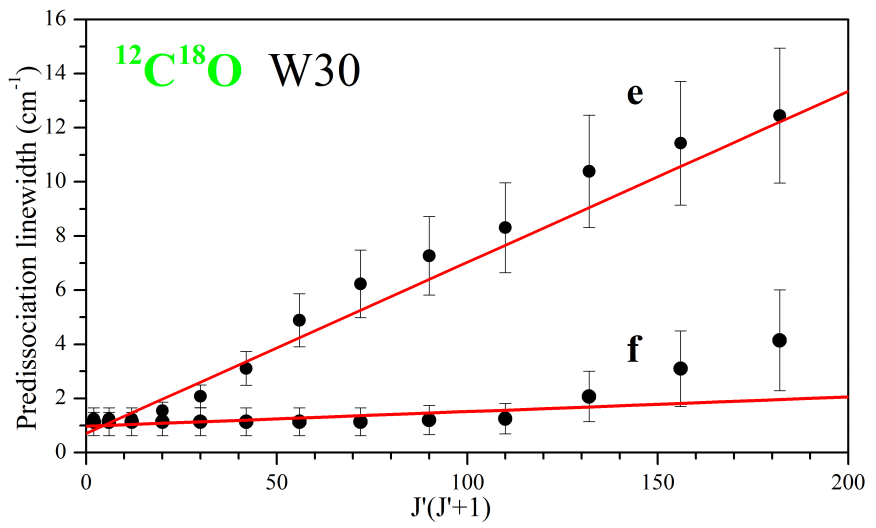

Fig. 18. ${ }^{12} \mathrm{C}^{18} \mathrm{O}$ measured predissociation linewidths for the $W\left(\mathrm{v}^{\prime}=3\right)-$ $X\left(\mathrm{v}^{\prime \prime}=0\right)$ band.

\subsubsection{Summary}

All the deduced $f$-values are collected in Table 1 for ${ }^{13} \mathrm{C}^{16} \mathrm{O}$ and Table 2 for ${ }^{12} \mathrm{C}^{18} \mathrm{O}$, and the Lorentzian predissociation rates appear in Table 3 for ${ }^{13} \mathrm{C}^{16} \mathrm{O}$ and Table 4 for ${ }^{12} \mathrm{C}^{18} \mathrm{O}$. They are compared with results from previous measurements (see tables). 
Table 3. ${ }^{13} \mathrm{C}^{16} \mathrm{O}$ predissociation rates for the $W(\mathrm{v}=0,1,2,3)-X(0)$ bands.

\begin{tabular}{lccc}
\hline \hline Level & Ref. & Parity & Predissociation rate $^{a}$ \\
\hline W00 & Present & $e$ & $0.220(0.060)+0.011(0.001) x^{b}$ \\
& Present & $f$ & $0.187(0.009)+0.002(0.001) x$ \\
& E06 & $e$ & $0.10+0.02 x^{c}$ \\
& E06 & $f$ & $0.10^{c}$ \\
& E94 & $e, f$ & $\leq 0.3+0.013(0.002) x$ \\
& L92b & $e, f$ & 0.3 \\
\hline E91 & $e, f$ & $2.92(0.15)+0.102(0.006) x$ \\
& Present $\left(J^{\prime}<8\right)^{d}$ & $e, f$ & $-4.77(0.24)+0.081(0.009) x$ \\
& Present $\left(J^{\prime}>7\right)^{d}$ & $e, f$ & $7.2^{c}$ \\
& E06 & $e, f$ & 3.3 \\
\hline W20 & E91 & $e, f$ & $0.76(0.21)+0.042(0.021) x$ \\
& Present & $e, f$ & $0.76(0.21)+0.021(0.010) x$ \\
& E06 & $e$ & $0.75(0.15)$ \\
& E94 & $f$ & $0.47(0.19)$ \\
& L92b & $e, f$ & $0.58(0.13)$ \\
& L92a & $e, f$ & 1.0 \\
\hline E91 & $e, f$ & $10.043)+0.0067(0.0011) x+[9.4(0.6)] \times 10^{2}$ \\
& Eresent & $e$ & 3.3 \\
& Present & $f$ & $1.998(0.064)+0.1500(0.0028) x$ \\
& E06 & $e, f$ & $1.680(0.021)+0.0124(0.0004) x$ \\
& E91 & $e, f$ & $1.0(0.1)+0.22(0.07) x$ \\
\hline
\end{tabular}

Notes. Uncertainties are given in parentheses (1 standard error). Comparison with previous predissociation rate results: E91 (Eidelsberg et al. 1991), L92a (Levelt et al.1992a), L92b (Levelt et al. 1992b), E94 (Eikema et al. 1994), and E06 (Eidelsberg et al. 2006). ${ }^{(a)}$ Predissociation rates in units of $\left(10^{11} \mathrm{~s}^{-1}\right) ;{ }^{(b)} x=J(J+1) ;{ }^{(c)}$ held fixed; ${ }^{(d)} 40$ mTorr results.

Table 4. ${ }^{12} \mathrm{C}^{18} \mathrm{O}$ predissociation rates for the $W(\mathrm{v}=0,1,2,3)-X(0)$ bands.

\begin{tabular}{cccc}
\hline \hline Level & Ref. & Parity & Predissociation rate $^{a}$ \\
\hline W00 & Present & $e$ & $0.226(0.021)+0.0147(0.0004) x^{b}$ \\
& Present & $f$ & $0.228(0.009)+0.00130(0.00007) x$ \\
& E91 & $e, f$ & 0.1 \\
\hline W10 & Present $\left(J^{\prime}<8\right)$ & $e, f$ & $1.87(0.53)+0.141(0.017) x$ \\
& Present $\left(J^{\prime}>7\right)$ & $e, f$ & $-5.96(0.60)+0.094(0.004) x$ \\
& E91 & $e, f$ & 3.3 \\
\hline W20 & Present & $e, f$ & $0.644(0.004)+0.00170(0.00087) x+[5.27(0.35)] \times 10^{-5} x^{2}$ \\
& E91 & $e, f$ & 1.0 \\
\hline W30 & Present & $e$ & $1.70(0.06)+0.164(0.004) x$ \\
& Present & $f$ & $1.41(0.02)+0.0145(0.0002) x$ \\
& E91 & $e, f$ & 3.3 \\
\hline
\end{tabular}

Notes. Uncertainties are given in parentheses (1 standard error). Comparison with previous predissociation rate results: E91 (Eidelsberg et al. 1991). ${ }^{(a)}$ Predissociation rates in units of $\left(10^{11} \mathrm{~s}^{-1}\right) .{ }^{(b)} x=J(J+1)$.

As indicated earlier, the accuracy of the $f$-value measurements is limited primarily by the $7 \%$ uncertainty on the calibration of the B00 $f$-value that is determined for ${ }^{12} \mathrm{C}^{16} \mathrm{O}$ from previous measurements (Stark et al. 1999; Federman et al. 2001). The consistency among measurements with different instrumental resolutions occurs for the most part because the studied upper levels have large predissociation rates. This leads to relatively broad line profiles and minimal systematic errors associated with the under-resolution of line profiles.

For ${ }^{13} \mathrm{C}^{16} \mathrm{O}$ (Table 1), even if the values from E06 and E91 for W10 and W30 agree more, we have more confidence in the present results obtained at much higher resolution.

We find a $J$ dependence in the predissociation rates for all $e$ - and $f$-parity levels of the four observed exited states. For the $\mathrm{W} 00$ and $\mathrm{W} 30$ bands, the predissociation rates are also parity dependent. The comparison with earlier results show overall agreement between determinations. The present results provide the first evidence for $J$-dependent rates for the set of $W-X$ bands. The isotopologue dependences in band $f$-values will be analyzed in terms of molecular structure in a forthcoming paper.

\subsection{The $92.97-93.37 \mathrm{~nm}$ region $(4 \mathrm{p}(2)$ and $5 p(0)$ complexes)}

The absorption spectra in the $93.2-93.5 \mathrm{~nm}$ region are very similar for both isotopologues, ${ }^{13} \mathrm{C}^{16} \mathrm{O}$ and ${ }^{12} \mathrm{C}^{18} \mathrm{O}$. This region comprises three well-resolved bands identified as $4 \mathrm{p} \pi{ }^{1} \Pi(2)-$ $X^{1} \Sigma^{+}(0), 5 \mathrm{p} \pi{ }^{1} \Pi(0)-X^{1} \Sigma^{+}(0)$, and $5 \mathrm{p} \sigma^{1} \Sigma^{+}(0)-X^{1} \Sigma^{+}(0)$ and one diffuse band of ${ }^{1} \Pi-{ }^{1} \Sigma$ character. The resolved bands are labeled $4 \mathrm{p} \pi{ }^{1} \Pi(2-0), 5 \mathrm{p} \pi{ }^{1} \Pi(0-0)$, and $5 \mathrm{p} \sigma^{1} \Sigma^{+}(0-0)$ for conciseness. Some unidentified lines appear within the $5 \mathrm{p} \pi{ }^{1} \Pi(0-0)$ and $5 \mathrm{p} \sigma^{1} \Sigma^{+}(0-0)$ bands, both in ${ }^{13} \mathrm{C}^{16} \mathrm{O}$ and ${ }^{12} \mathrm{C}^{18} \mathrm{O}$. Room temperature and cold spectra are shown with the identification 
M. Eidelsberg et al.: High-resolution study of oscillator strengths and predissociation rates for ${ }^{13} \mathrm{C}^{16} \mathrm{O}$ and ${ }^{12} \mathrm{C}^{18} \mathrm{O}$

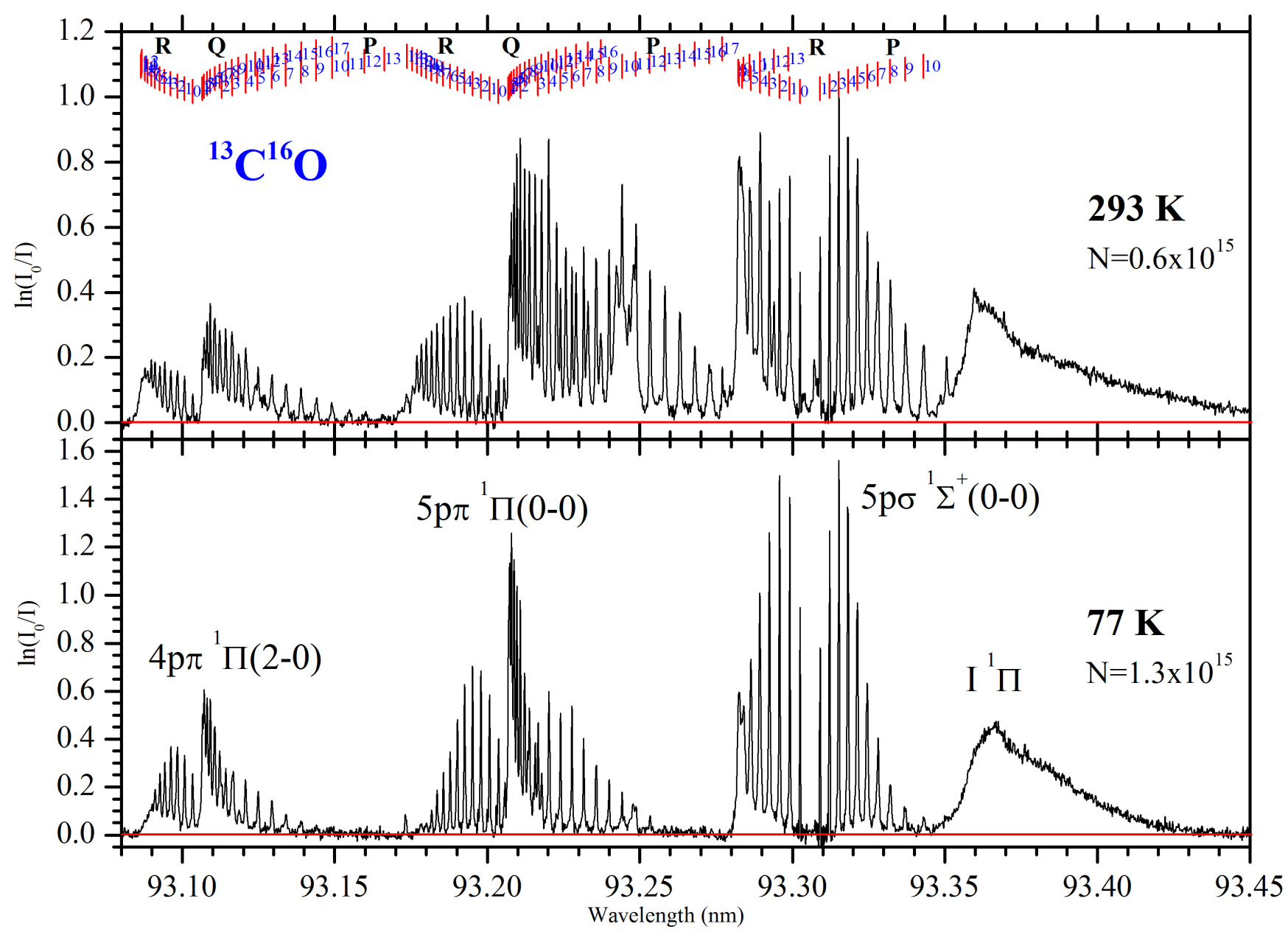

Fig. 19. ${ }^{13} \mathrm{C}^{16} \mathrm{O} 4 \mathrm{p}(2)$ and $5 \mathrm{p}(0)$ Rydberg complexes and surrounding region recorded at $293 \mathrm{~K}$ (top) and $77 \mathrm{~K}$ (bottom). The column-density $N$ is in $\mathrm{cm}^{-2}$. Line assignments in each band $\left(4 \mathrm{p} \pi{ }^{1} \Pi(2-0), 5 \mathrm{p} \pi^{1} \Pi(0-0)\right.$, and $\left.5 \mathrm{p} \sigma^{1} \Sigma^{+}(0-0)\right)$ are shown on the top panel.

of the observed rotational lines for ${ }^{13} \mathrm{C}^{16} \mathrm{O}$ in Fig. 19 and for ${ }^{12} \mathrm{C}^{18} \mathrm{O}$ in Fig. 20. Very similar fitting procedures worked well for both isotopologues, and the combined results are discussed below for each band.

\subsection{1. $4 p(2)$ complex}

Fits of the $4 \mathrm{p} \pi{ }^{1} \Pi(2)-X^{1} \Sigma^{+}(0)$ band, which were recorded at room temperature and $77 \mathrm{~K}$ for ${ }^{13} \mathrm{C}^{16} \mathrm{O}$ (Fig. 21) and at room temperature for ${ }^{12} \mathrm{C}^{18} \mathrm{O}$ (Fig. 22) have been obtained using HönlLondon factors that are appropriate for a pure $\Pi-\Sigma$ transition. The Lorentzian linewidth and its linear dependence in $J^{\prime}\left(J^{\prime}+1\right)$ have been calculated and introduced in the fitting procedure as free parameters for the $e$ - and $f$-components for both isotopologues. A similar trend is seen in both room temperature and $77 \mathrm{~K}$ spectra for both isotopologues.

Only a few weak lines labeled $\mathbf{a}$ in Figs. 27 and 28 have been observed in our $5 \mathrm{p} \pi{ }^{1} \Pi(0-0)$ band spectra within the R-branch for ${ }^{13} \mathrm{C}^{16} \mathrm{O}$ and the $\mathrm{P}$-branch for ${ }^{12} \mathrm{C}^{18} \mathrm{O}$. They are likely due to the weak band, $4 \mathrm{p} \sigma^{1} \Sigma^{+}(2)-X^{1} \Sigma^{+}(0)$, which is previously observed in our ${ }^{12} \mathrm{C}^{16} \mathrm{O}$ spectra (E12). The corresponding $f$-value is very small for ${ }^{13} \mathrm{C}^{16} \mathrm{O}$ and negligible for ${ }^{12} \mathrm{C}^{18} \mathrm{O}$.

\subsection{2. $5 p(0)$ complex}

The $5 \mathrm{p} \pi{ }^{1} \Pi(0)$ and $5 \mathrm{p} \sigma \Sigma^{+}(0)$ components of the Rydberg $5 \mathrm{p}(0)$ complex are well characterized in both isotopologues. The $5 \mathrm{p} \pi$ ${ }^{1} \Pi(0)-X^{1} \Sigma^{+}(0)$ band is clearly observable until $J^{\prime}=16$ for the R-, P-, and Q-branch lines. The $5 \mathrm{p} \sigma^{1} \Sigma^{+}(0)-X^{1} \Sigma^{+}(0)$ band is characterized by a conspicuous R-branch head in both isotopologues reflecting the interactions within the $5 \mathrm{p}$ complex.

4.2.2.1. $5 \mathrm{p} \pi{ }^{1} \Pi(0)-X^{1} \Sigma^{+}(0)$

First, a simulation was made of the entire $5 \mathrm{p} \pi{ }^{1} \Pi(0)-X^{1} \Sigma^{+}(0)$ band by assuming unperturbed Hönl-London factors. Upon comparison with the measured spectra, the simulated P-branch appears stronger than expected, and the R-branch weaker. Consequently, a fitting procedure assuming a single $f$-value for a band was not used. Then, an individual fit was calculated for each rotationally resolved R-, P-, and Q-branch line and provided information on the $J$ dependence of the band oscillator strength, as well as on the $J$ dependence of the predissociation linewidths. The $J$ dependence of $f$-values for the Q-lines is adequately represented by a linear fit to $J^{\prime}\left(J^{\prime}+1\right)$. The P- and R-line $f$-values are fit to higher order polynomials with a common rotationless $f$-value, $f\left(J^{\prime}=0\right)$, as shown in Fig. 23 for ${ }^{13} \mathrm{C}^{16} \mathrm{O}$ and Fig. 24 for ${ }^{12} \mathrm{C}^{18} \mathrm{O}$.

The most striking features in Figs. 23 and 24 are the rapidly increasing strength of the P-branch lines with rotational quantum number and the relative weakness of the R-branch lines. The measured oscillator strengths are reported in terms of a polynomial in $x=J^{\prime}\left(J^{\prime}+1\right), f\left(J^{\prime}\right)=f(0)+f(x)$ that represents the rotational dependence of the band $f$-value. The rotationless band $f$-value, $f(0)$, and the higher-order polynomial $f(x)$ are reported in Table 5 for ${ }^{13} \mathrm{C}^{16} \mathrm{O}$ and in Table 6 for ${ }^{12} \mathrm{C}^{18} \mathrm{O}$. 


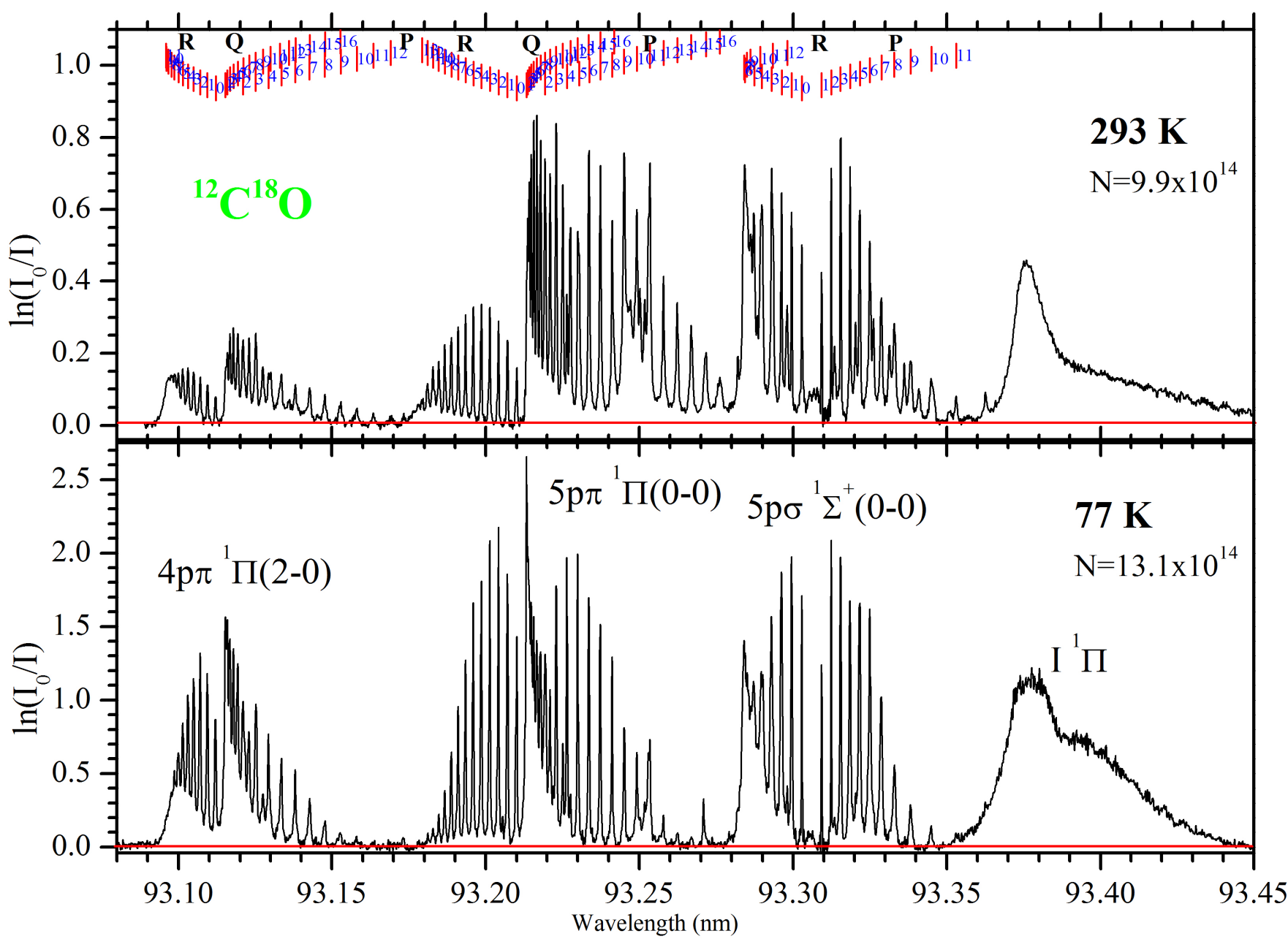

Fig. 20. ${ }^{12} \mathrm{C}^{18} \mathrm{O} 4 \mathrm{p}(2)$ and $5 \mathrm{p}(0)$ Rydberg complexes and surrounding region recorded at $293 \mathrm{~K}$ (top) and $77 \mathrm{~K}$ (bottom). The column-density $N$ is in $\mathrm{cm}^{-2}$. Line assignments in each band $\left(4 \mathrm{p} \pi^{1} \Pi(2-0), 5 \mathrm{p} \pi^{1} \Pi(0-0)\right.$, and $\left.5 \mathrm{p} \sigma^{1} \Sigma^{+}(0-0)\right)$ are shown on the top panel .

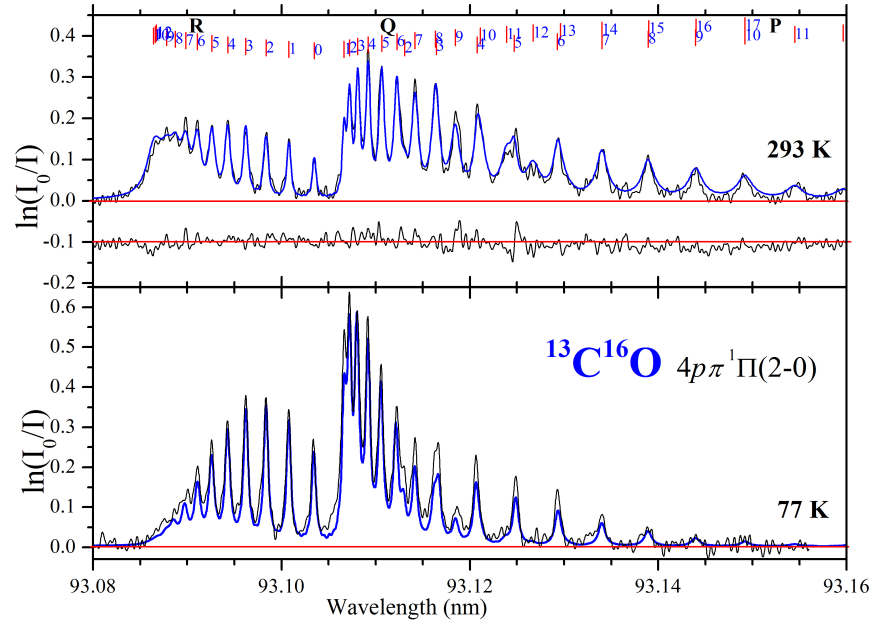

Fig. 21. ${ }^{13} \mathrm{C}^{16} \mathrm{O}$ experimental spectrum (black line) and fit (blue line) of the $4 \mathrm{p} \pi{ }^{1} \Pi(2-0)$ band recorded at $293 \mathrm{~K}$ (top) with the fitting residuals shifted by -0.1 and at $77 \mathrm{~K}$ (bottom).

The predissociation linewidths were found to be parity dependent (Figs. 25 and 26). The predissociation rates deduced from the line broadening of the Q-lines are represented by a linear proportionality in $J^{\prime}\left(J^{\prime}+1\right)$. The high members of the P-branch exhibit distinct line broadening for $J^{\prime}>7$ and

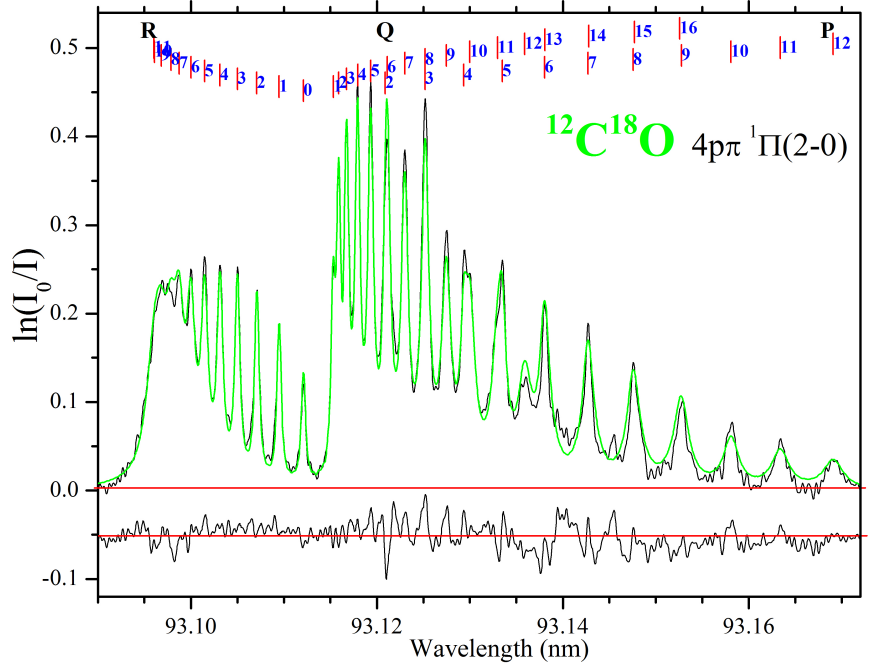

Fig. 22. ${ }^{12} \mathrm{C}^{18} \mathrm{O}$ experimental spectrum (black line) and fit (green line) of the $4 \mathrm{p} \pi{ }^{1} \Pi(2-0)$ band recorded at $293 \mathrm{~K}$ with the fitting residuals shifted by -0.05 .

predissociation rates are represented by two different functions in $J^{\prime}\left(J^{\prime}+1\right)$ as reported in Tables 5 and 6 .

A room-temperature $f$-value, $f_{\text {int }}$, which is obtained from a fit of the entire band with corrected Hönl-London factors and 
M. Eidelsberg et al.: High-resolution study of oscillator strengths and predissociation rates for ${ }^{13} \mathrm{C}^{16} \mathrm{O}$ and ${ }^{12} \mathrm{C}^{18} \mathrm{O}$

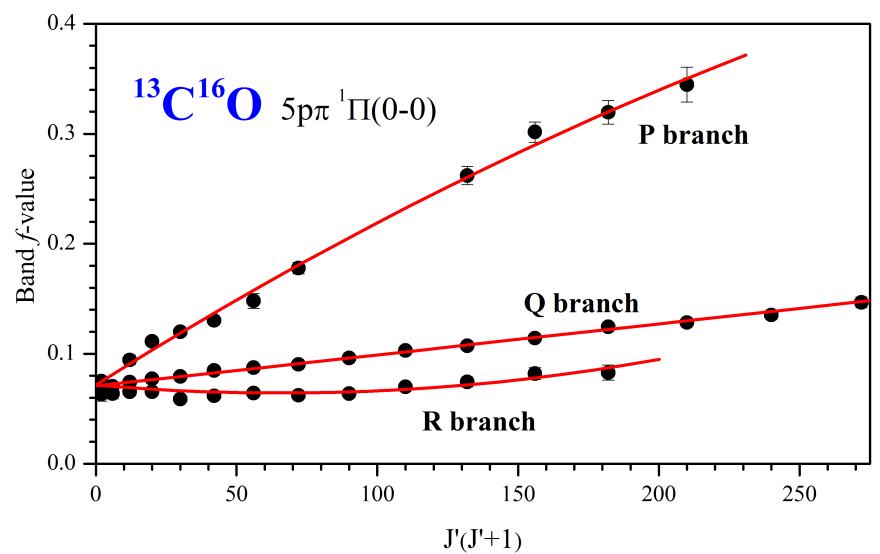

Fig. 23. ${ }^{13} \mathrm{C}^{16} \mathrm{O}$ oscillator strengths for the $5 \mathrm{p} \pi{ }^{1} \Pi(0-0)$ band.

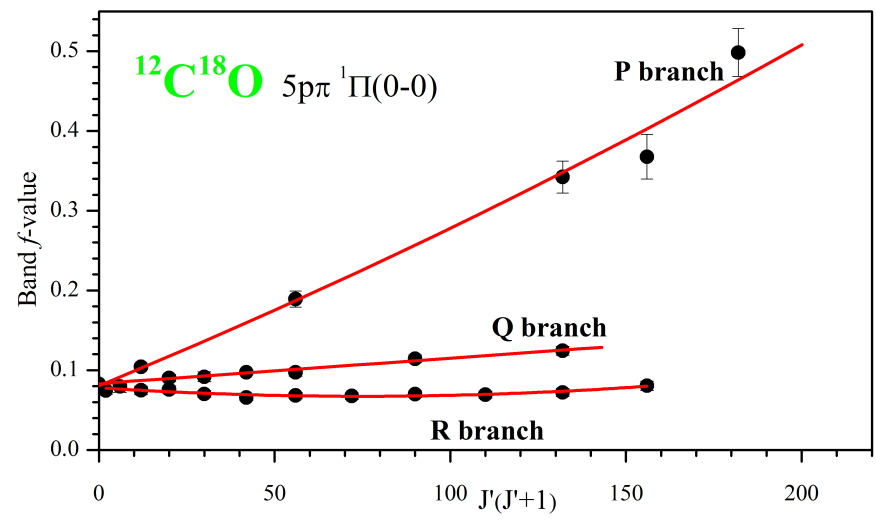

Fig. 24. ${ }^{12} \mathrm{C}^{18} \mathrm{O}$ oscillator strengths for the $5 \mathrm{p} \pi{ }^{1} \Pi(0-0)$ band.

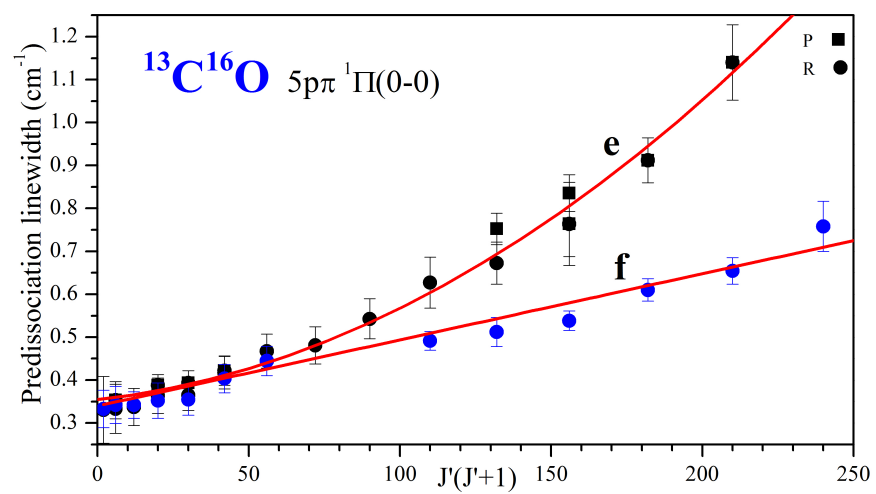

Fig. 25. ${ }^{13} \mathrm{C}^{16} \mathrm{O}$ measured predissociation linewidths for the $5 \mathrm{p} \pi$ ${ }^{1} \Pi(0-0)$ band.

linewidths (Figs. 27 and 28) as determined by the fit of individual $\mathrm{R}-, \mathrm{P}-$, and Q-branch lines, is also reported in Tables 5 and 6 for ${ }^{13} \mathrm{C}^{16} \mathrm{O}$ and ${ }^{12} \mathrm{C}^{18} \mathrm{O}$, respectively.

\subsubsection{2. $5 \mathrm{p} \sigma^{1} \Sigma^{+}(0)-X^{1} \Sigma^{+}(0)$}

The same procedure used for $5 \mathrm{p} \pi{ }^{1} \Pi(0-0)$ was applied to the $5 \mathrm{p} \sigma^{1} \Sigma^{+}(0)-X^{1} \Sigma^{+}(0)$ band. The line $f$-values for five P-lines which are derived from measurements in ${ }^{13} \mathrm{C}^{16} \mathrm{O}$, and nine $\mathrm{P}$-lines in ${ }^{12} \mathrm{C}^{18} \mathrm{O}$ were fit to linearly decreasing functions of $J^{\prime}\left(J^{\prime}+1\right)$ (See Fig. 29 for ${ }^{13} \mathrm{C}^{16} \mathrm{O}$ and Fig. 30 for ${ }^{12} \mathrm{C}^{18} \mathrm{O}$ ). The strengths of the four R-branch lines, which were fitted individually in the ${ }^{13} \mathrm{C}^{16} \mathrm{O}$ spectra, increase rapidly until $J^{\prime}=5$. From using a simple Hönl-London progression of line strengths and fitting the entire band, it was also clear that higher $J^{\prime}$ lines continue to be perturbed. The comparison of a synthetic band model

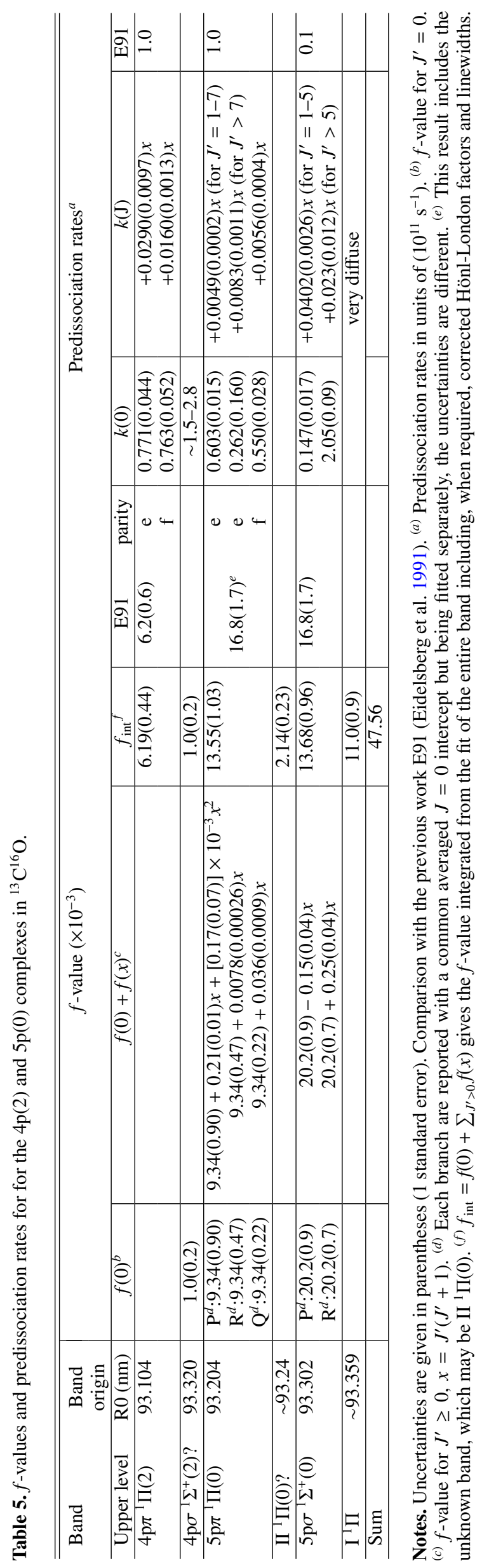

A96, page 11 of 15 


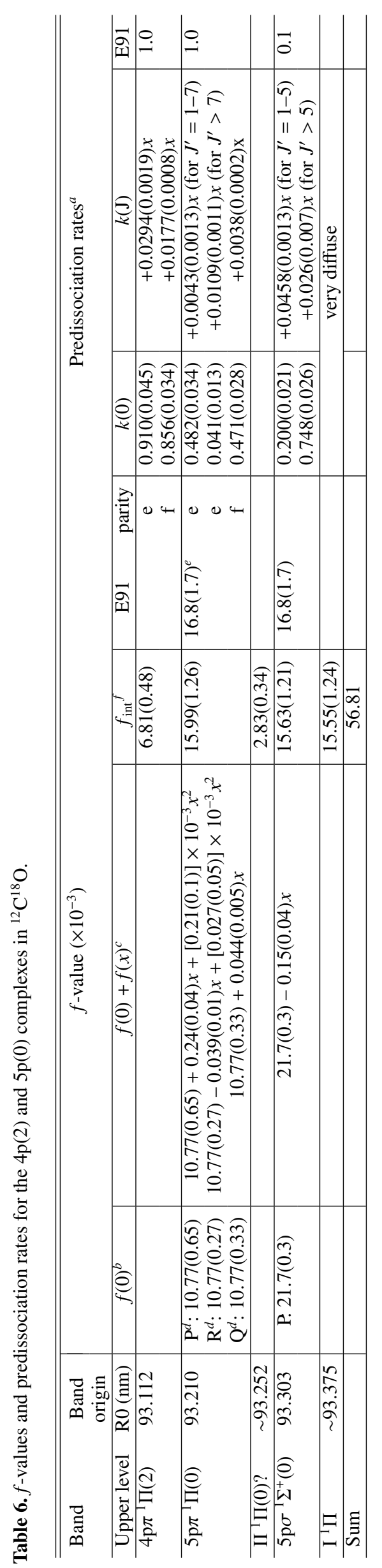

$\dot{0} \stackrel{\oplus}{\Xi}$

월

를

흐를 흘

政高

ف. 氙

居

을

可起

의

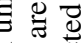

$\Xi \stackrel{0}{0}$

要

ธี Ð

矛

\&

$\therefore$ 을

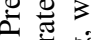

छ

穴总

大े छ

สं 000

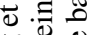

잉.

这

훙워

过类

可葛

II용

응

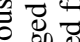

एँ

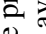

ฮี.引

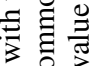

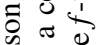

월

更的

ठิ उ.

훙ㅎㅇ

엥

䒕 +

홍

क ق

की

\&s

$\dot{0} \dot{0}$

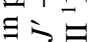

$\approx 8$

: 11

象

光 $0 . \overline{0}$

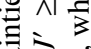

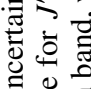

空

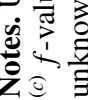

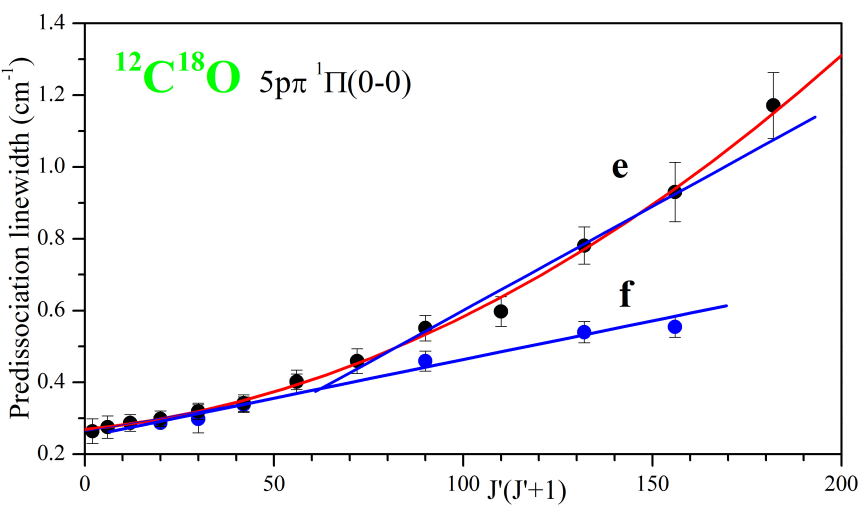

Fig. 26. ${ }^{12} \mathrm{C}^{18} \mathrm{O}$ measured predissociation linewidths for the $5 \mathrm{p} \pi$ ${ }^{1} \Pi(0-0)$ band

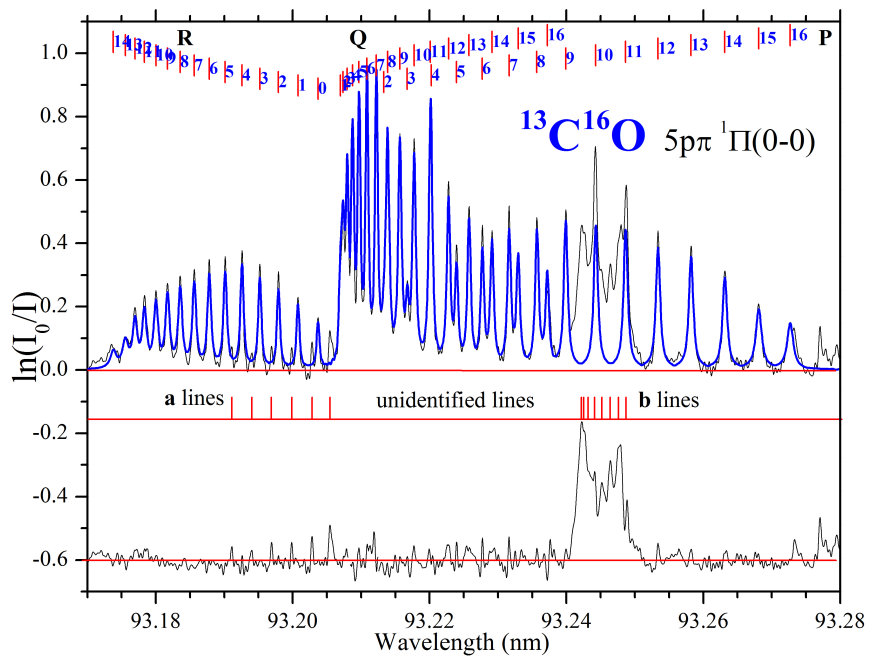

Fig. 27. ${ }^{13} \mathrm{C}^{16} \mathrm{O}$ experimental spectrum (black line) and fit (blue line) of the $5 \mathrm{p} \pi{ }^{1} \Pi(0-0)$ band recorded at $293 \mathrm{~K}$ with the fitting residuals shifted by -0.6 . Two series of unidentified lines, labeled $\mathbf{a}$ and $\mathbf{b}$, are also shown (see text).

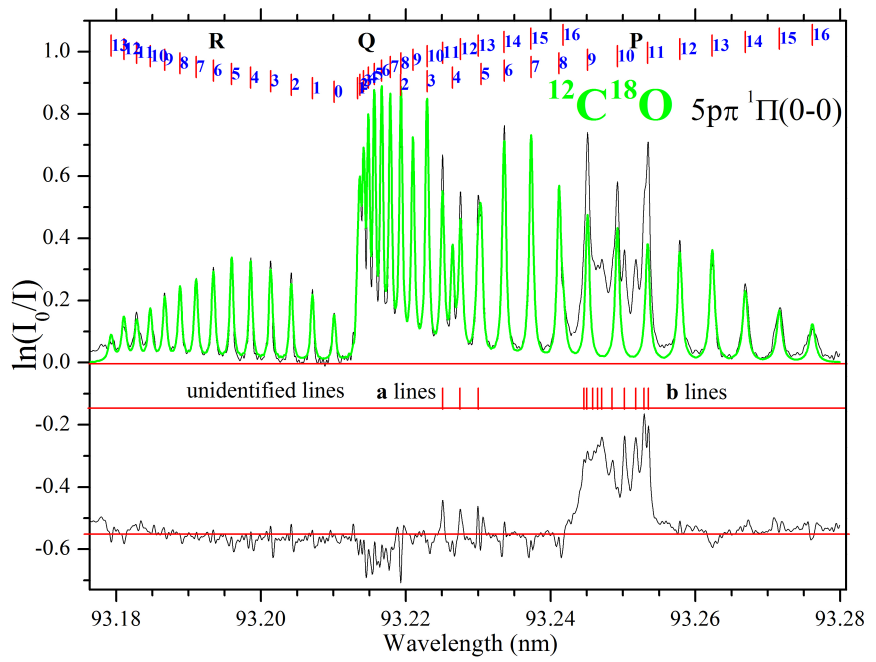

Fig. 28. ${ }^{12} \mathrm{C}^{18} \mathrm{O}$ experimental spectrum (black line) and fit (green line) of the $5 \mathrm{p} \pi{ }^{1} \Pi(0-0)$ band recorded at $293 \mathrm{~K}$ with the fitting residuals shifted by -0.5 . Two series of unidentified lines, labeled $\mathbf{a}$ and $\mathbf{b}$, are also shown (see text).

with our measured spectra indicates that the R-branch lines may be stronger than predicted by Hönl-London factors that are appropriate for a pure ${ }^{1} \Pi-{ }^{1} \Sigma$ transition. The R-branch in ${ }^{12} \mathrm{C}^{18} \mathrm{O}$ 
M. Eidelsberg et al.: High-resolution study of oscillator strengths and predissociation rates for ${ }^{13} \mathrm{C}^{16} \mathrm{O}$ and ${ }^{12} \mathrm{C}^{18} \mathrm{O}$

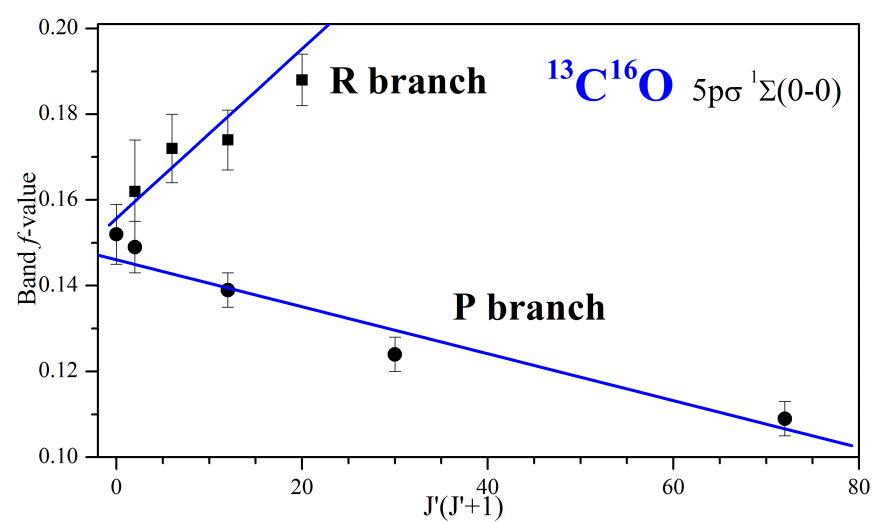

Fig. 29. ${ }^{13} \mathrm{C}^{16} \mathrm{O}$ oscillator strengths for the $5 \mathrm{p} \sigma^{1} \Sigma^{+}(0-0)$ band.

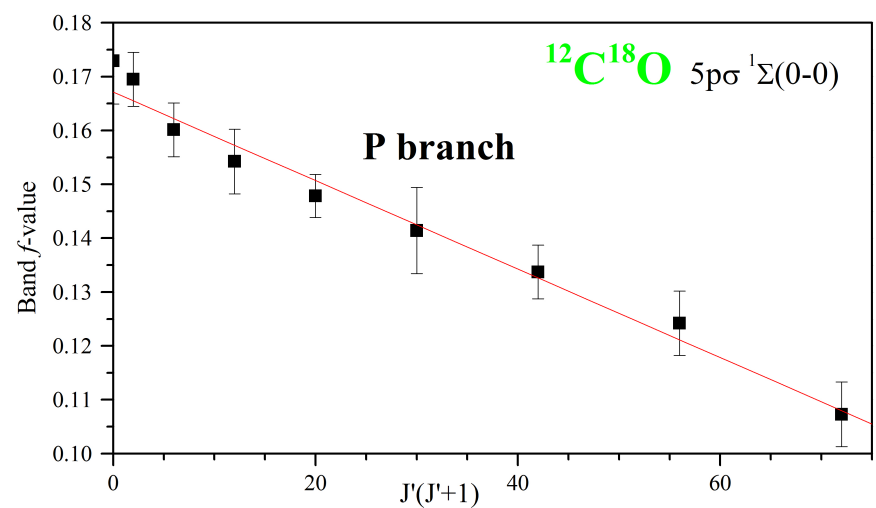

Fig. 30. ${ }^{12} \mathrm{C}^{18} \mathrm{O}$ oscillator strengths for the $5 \mathrm{p} \sigma^{1} \Sigma^{+}(0-0)$ band.

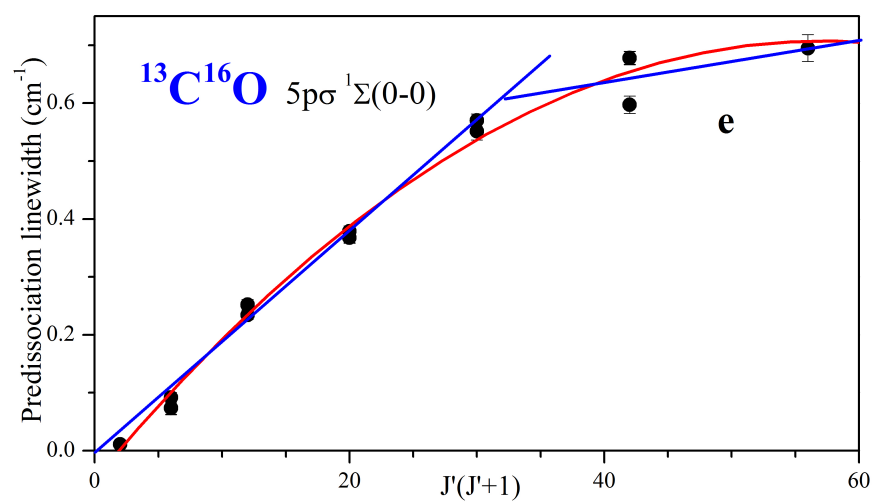

Fig. 31. ${ }^{13} \mathrm{C}^{16} \mathrm{O}$ measured predissociation linewidths for the $5 \mathrm{p} \sigma$ ${ }^{1} \Sigma^{+}(0-0)$ band.

is similarly perturbed, although no lines could be reliably fitted individually. The rotationless $f$-values and their fitted $J^{\prime}$ dependence are reported in Table 5 for ${ }^{13} \mathrm{C}^{16} \mathrm{O}$ and Table 6 for ${ }^{12} \mathrm{C}^{18} \mathrm{O}$.

The predissociation linewidths reported in Fig. 31 for ${ }^{13} \mathrm{C}^{16} \mathrm{O}$ and Fig. 32 for ${ }^{12} \mathrm{C}^{18} \mathrm{O}$ increase with $J^{\prime}$ at a non-constant rate. Two linear fits, for low and high $J^{\prime}$, are used to reproduce the $J^{\prime}\left(J^{\prime}+1\right)$ dependences.

As for the $5 \mathrm{p} \pi{ }^{1} \Pi(0-0)$ band, a room-temperature $f$-value, $f_{\text {int }}$, has been determined from the fit of the entire band with corrected Hönl-London factors and linewidths, as determined by the fit of individual R- and P-lines (Figs. 33 and 34) and is reported in Tables 5 and 6 for ${ }^{13} \mathrm{C}^{16} \mathrm{O}$ and ${ }^{12} \mathrm{C}^{18} \mathrm{O}$.

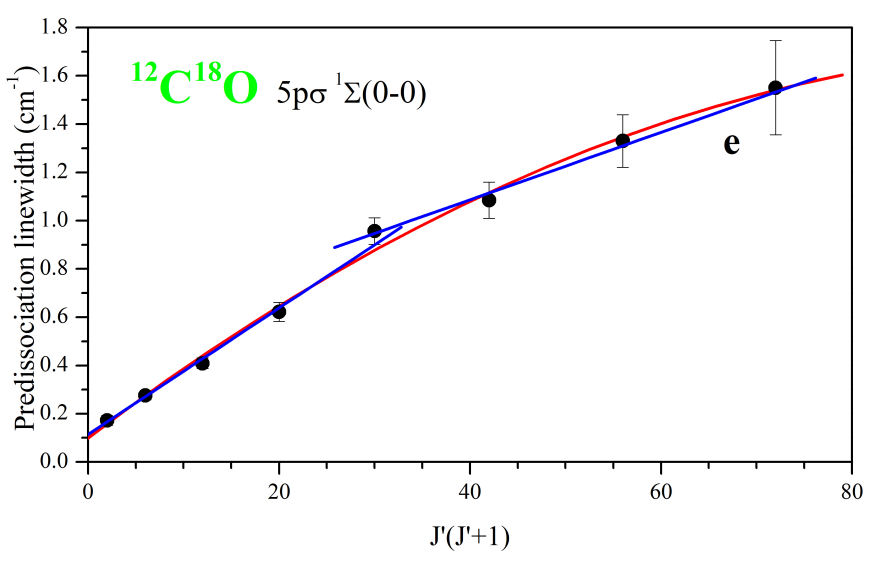

Fig. 32. ${ }^{12} \mathrm{C}^{18} \mathrm{O}$ measured predissociation linewidths for the $5 \mathrm{p} \sigma$ ${ }^{1} \Sigma^{+}(0-0)$ band.

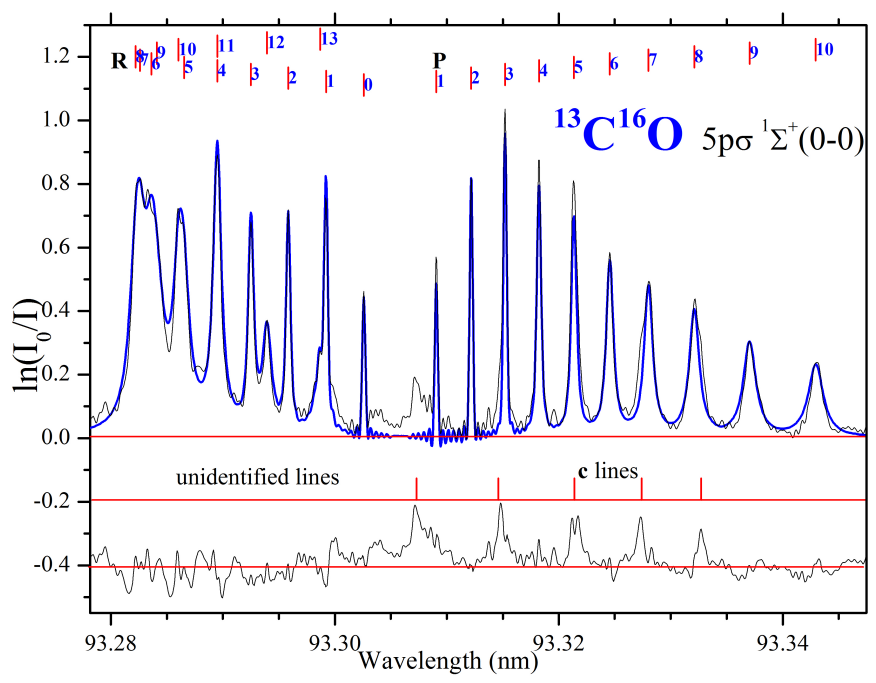

Fig. 33. ${ }^{13} \mathrm{C}^{16} \mathrm{O}$ experimental spectrum (black line) and fit (blue line) of the $5 \mathrm{p} \sigma^{1} \Sigma^{+}(0-0)$ band recorded at $293 \mathrm{~K}$ with the fitting residuals shifted by -0.4 . Regularly spaced unidentified lines, labeled $\mathbf{c}$, are also shown (see text).

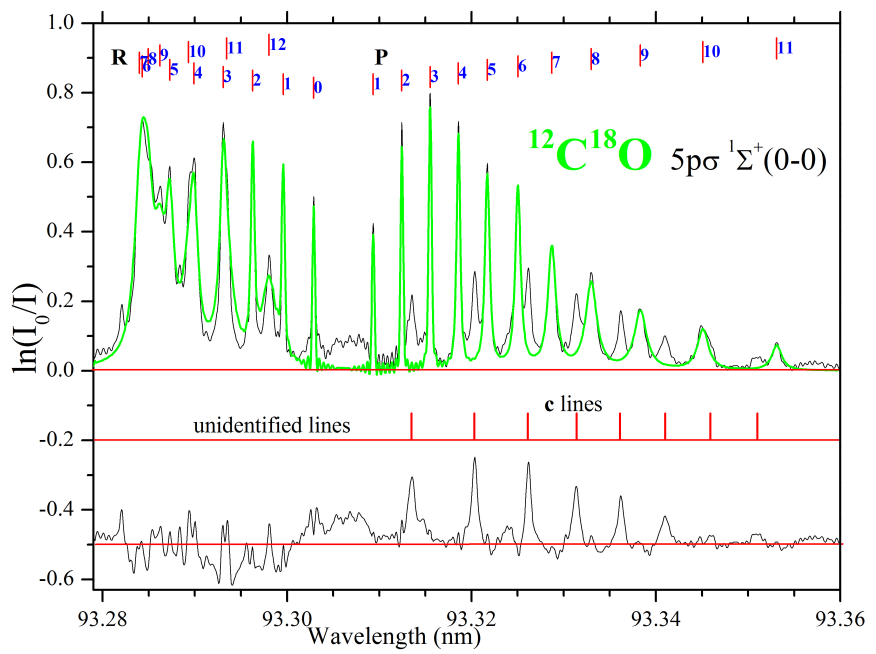

Fig. 34. ${ }^{12} \mathrm{C}^{18} \mathrm{O}$ experimental spectrum (black line) and fit (green line) of the $5 \mathrm{p} \sigma^{1} \Sigma^{+}(0-0)$ band recorded at $293 \mathrm{~K}$ with the fitting residuals shifted by -0.5 . Regularly spaced unidentified lines, labeled $\mathbf{c}$, are also shown (see text). 
Table 7. Wavelengths (in $\mathrm{nm}$ ) of the resolved unidentified lines appearing in the $5 \mathrm{p} \pi{ }^{1} \Pi(0)$ and $5 \mathrm{p} \sigma{ }^{1} \Sigma^{+}(0)$ bands for ${ }^{13} \mathrm{C}^{16} \mathrm{O}$ and ${ }^{12} \mathrm{C}^{18} \mathrm{O}$.

\begin{tabular}{l|c|c|c}
\hline \hline \multicolumn{2}{c|}{} & \multicolumn{2}{c}{${ }^{13} \mathrm{C}^{18} \mathrm{O}$} \\
\hline $\begin{array}{l}\text { 5p }{ }^{1}{ }^{1} \Pi(0) \\
\text { cf. Fig. 27 }\end{array}$ & $\begin{array}{c}5 \mathrm{p} \sigma^{1} \Sigma^{+}(0) \\
\text { cf. Fig. 33 }\end{array}$ & $\begin{array}{c}5 \mathrm{p} \pi^{1} \Pi(0) \\
\text { cf. Fig. 28 }\end{array}$ & $\begin{array}{c}5 \mathrm{p} \sigma^{1} \Sigma^{+}(0) \\
\text { cf. Fig. 34 }\end{array}$ \\
\hline label a & label c & label a & label c \\
93.1911 & 93.3073 & 93.2251 & 93.3135 \\
93.1940 & 93.3146 & 93.2275 & 93.3203 \\
93.1969 & 93.3214 & 93.2300 & 93.3261 \\
93.1999 & 93.3274 & & 93.3314 \\
93.2029 & 93.3327 & & 93.3361 \\
93.2055 & & & 93.3410 \\
& & & 93.3459 \\
& & & 93.3510 \\
label b & & label b & \\
93.2422 & & 93.2446 & \\
93.2425 & & 93.2450 & \\
93.2432 & & 93.2458 & \\
93.2441 & & 93.2465 & \\
93.2452 & & 93.2471 & \\
93.2464 & & 93.2485 & \\
93.2476 & & 93.2502 & \\
93.2487 & & 93.2518 & \\
& & 93.2529 & \\
& & 93.2535 & \\
\hline
\end{tabular}

Notes. Uncertainty is $\sim \pm 0.1 \mathrm{pm}$.

\subsection{3. $I^{1} \Pi-{ }^{1} \Sigma^{+}$}

A predissociation-broadened band is observed in ${ }^{12} \mathrm{C}^{16} \mathrm{O}(\mathrm{E} 12)$ which overlaps the P-branch of $5 \mathrm{p} \sigma^{1} \Sigma^{+}(0)-X^{1} \Sigma^{+}(0)$, and is identified as the $\mathrm{I}^{1} \Pi-{ }^{1} \Sigma^{+}$transition. This relies on a deperturbation analysis (Eidelsberg et al. 2004b). A similar band appears in the ${ }^{13} \mathrm{C}^{16} \mathrm{O}$ and ${ }^{12} \mathrm{C}^{18} \mathrm{O}$ spectra that is shifted and well separated from the P-branch of $5 \mathrm{p} \sigma^{1} \Sigma^{+}(0)-X^{1} \Sigma^{+}(0)$ (see Figs. 19 and 20). Because of the very strong predissociation, the fitting procedure was impossible to apply. Instead, we have determined the band oscillator strength, according to Eq. (2), by measuring the area at three pressures, 15,25 and $40 \mu$ bar, for ${ }^{13} \mathrm{C}^{16} \mathrm{O}$ and 8 , 22, and $48 \mu$ bar for ${ }^{12} \mathrm{C}^{18} \mathrm{O}$. These results are then extrapolated to zero pressure by considering the error bars at the three different pressures. The corresponding values are given in Tables 5 and 6.

\subsubsection{Unidentified bands}

There are unidentified lines (labeled b) between 93.242 and $93.249 \mathrm{~nm}$ in ${ }^{13} \mathrm{C}^{16} \mathrm{O}$ (Fig. 27) and between 93.245 and $93.254 \mathrm{~nm}$ in ${ }^{12} \mathrm{C}^{18} \mathrm{O}$ (Fig. 28). These appear within the P-branch of the $5 \mathrm{p} \pi{ }^{1} \Pi(0-0)$ band, and their measured wavelengths are reported in Table 7. The procedure applied for the determination of the $f$-value for the $\mathrm{I}^{1} \Pi-{ }^{1} \Sigma^{+}$band was used again for the calculation of the oscillator strengths of these unidentified lines. Subtracting the area of the fitted P-branch of the $5 \mathrm{p} \sigma^{1} \Sigma^{+}(0-0)$ band from the area of the experimental spectrum in the same wavelength region at different pressures allowed us to estimate the oscillator strength of these lines reported in Tables 5 and 6 . These lines could be attributed to the II ${ }^{1} \Pi-{ }^{1} \Sigma^{+}$band, which is observed in ${ }^{12} \mathrm{C}^{16} \mathrm{O}(\mathrm{E} 12)$.
This can be observed in Fig. 35 when comparing the complete $4 p(2)$ and $5 p(0)$ regions for ${ }^{12} \mathrm{C}^{16} \mathrm{O}$ (top) and ${ }^{12} \mathrm{C}^{18} \mathrm{O}$ (bottom). The procedure used above for lines labeled $\mathbf{b}$ has been applied to determine the $f$-value of the six lines labeled $\mathbf{a}$, which appear between 93.19 and $93.21 \mathrm{~nm}$ within the R-branch of the $5 \mathrm{p} \pi{ }^{1} \Pi(0-0)$ band in ${ }^{13} \mathrm{C}^{16} \mathrm{O}$. These lines must be due to the $4 \mathrm{p} \sigma(2-0)$ band observed in ${ }^{13} \mathrm{C}^{16} \mathrm{O}$ (see Fig. 35). The $f$-value is very small. The $f$-value of the three a lines, which appear in ${ }^{12} \mathrm{C}^{18} \mathrm{O}$ around $93.23 \mathrm{~nm}$ and are likely due to the aforementioned $4 \mathrm{p} \sigma(2-0)$ band, has not be determined.

Some regularly spaced lines, which are labeled $\mathbf{c}$, are visible inside the P-branch of the $5 \mathrm{p} \sigma^{1} \Sigma(0-0)$ band in ${ }^{13} \mathrm{C}^{16} \mathrm{O}$ (Fig. 33) and in ${ }^{12} \mathrm{C}^{18} \mathrm{O}$ (Fig. 34) but are not observed in the higher pressure cold spectra (Figs. 19 and 20). These lines appear to be blended in the ${ }^{13} \mathrm{C}^{16} \mathrm{O}$ spectrum.

The error bars on the oscillator strengths of the unidentified bands have been propagated from the error in the fitting of the $5 \mathrm{p} \sigma(0-0)$ band after its removal.The signal-to-noise ratio is then more poor as it is reflected in the larger quoted uncertainties.

\subsubsection{Final results}

All deduced $f$-values and predissociation rates are listed in Table 5 for ${ }^{13} \mathrm{C}^{16} \mathrm{O}$ and in Table 6 for ${ }^{12} \mathrm{C}^{18} \mathrm{O}$ for the three resolved bands and for the diffuse band, respectively. Comparisons are made with previous existing results (Eidelsberg et al. 1991). As with the $W-X$ bands, the significant amounts of broadening present minimize the effects of analyzing optically thick lines, which results in similar $f$-values from measurements with different spectral resolution. Furthermore, we find no evidence for absorption within the continuum, as seen in ${ }^{12} \mathrm{C}^{16} \mathrm{O}$ spectra (E12). Upon summing the results for $f_{\text {int }}$ for ${ }^{13} \mathrm{C}^{16} \mathrm{O}$ and ${ }^{12} \mathrm{C}^{18} \mathrm{O}$, we obtain $47.6 \times 10^{-3}$ and $56.8 \times 10^{-3}$, respectively, while the results in $\mathrm{E} 12$ for ${ }^{12} \mathrm{C}^{16} \mathrm{O}$ yield $58.0 \times 10^{-3}$, which includes the continuum absorption. It is not clear if the smaller sum for ${ }^{13} \mathrm{C}^{16} \mathrm{O}$ is significant in light of the $\sim 10 \%$ uncertainty for each band. The possible differences will be explored further in a future paper.

\section{Concluding remarks}

In the current study, eight bands are observed in the photoabsorption spectra of ${ }^{13} \mathrm{C}^{16} \mathrm{O}$ and ${ }^{12} \mathrm{C}^{18} \mathrm{O}$ for transitions that involve $W-X$ bands and the $4 \mathrm{p} 5 \mathrm{p}$ complex in the wavelength range between 92.5 and $97.5 \mathrm{~nm}$. Band oscillator strengths were derived from an overall fit of each band, and $J$-dependent oscillator strengths for the bands for which line-by-line fits have been performed. Predissociation linewidths were determined for all individually resolved lines or by fitting some bands to a simple $J$ dependence. These measurements allow for a determination of the dissociation rate for these completely predissociating bands. A majority of the integrated photoabsorption and photodissociation cross sections of CO between 92.5 and $97.5 \mathrm{~nm}$ results from the bands observed here.

In the course of this study, a number of perturbations are seen for the first time. They are revealed by the variations in $J$ dependence for $f$-values and predissociation rates. Additional theoretical analysis and computations are needed to shed light on the interactions involved. Such calculations will also provide insight into the differences found for ${ }^{13} \mathrm{C}^{16} \mathrm{O}$ and ${ }^{12} \mathrm{C}^{18} \mathrm{O}$ here and in ${ }^{12} \mathrm{C}^{16} \mathrm{O}$ in E12. The first efforts in this direction (Lefèbvre-Brion \& Eidlesberg 2012; Heays et al., in prep.) show that continued investigations of CO Rydberg states have much 
M. Eidelsberg et al.: High-resolution study of oscillator strengths and predissociation rates for ${ }^{13} \mathrm{C}^{16} \mathrm{O}$ and ${ }^{12} \mathrm{C}^{18} \mathrm{O}$

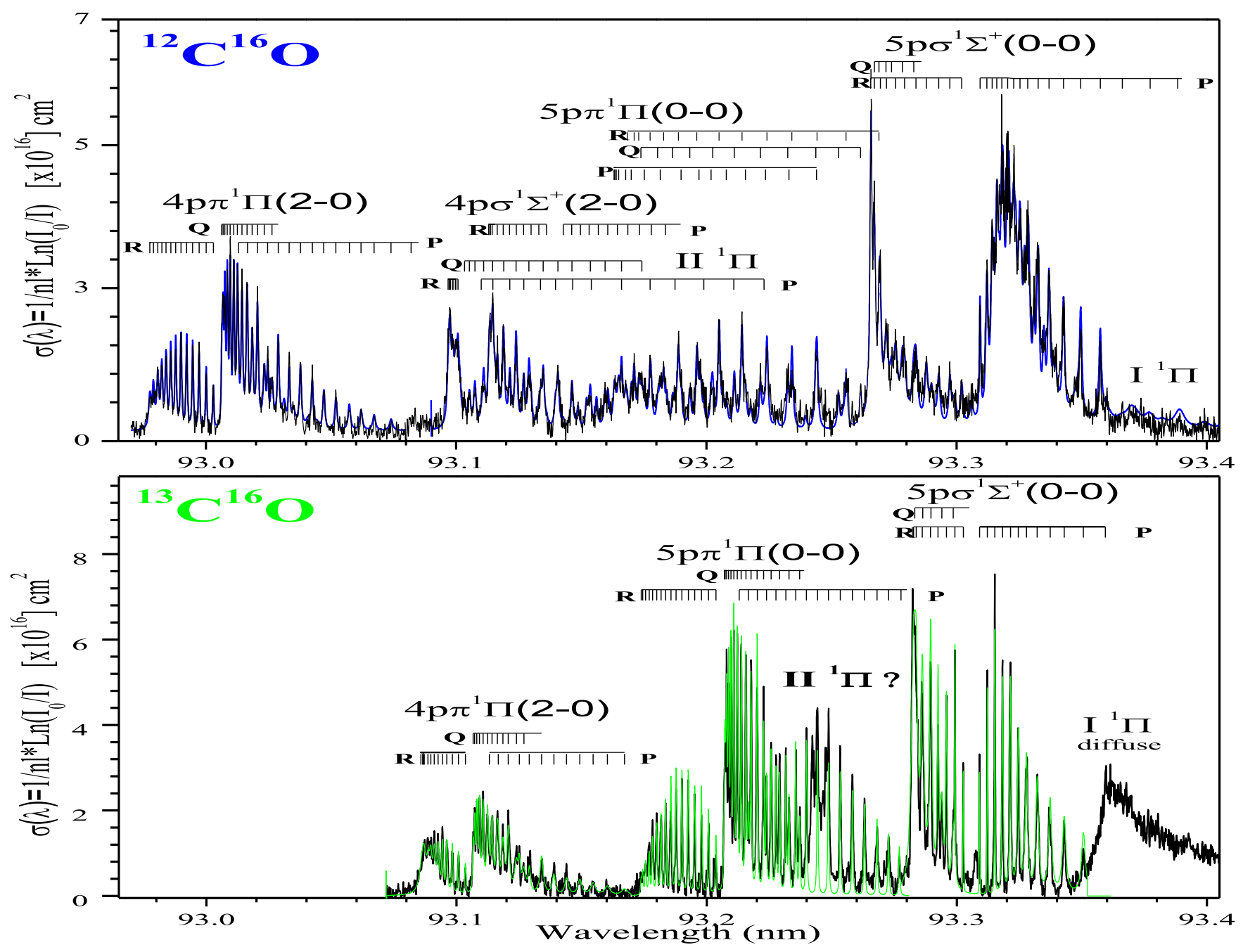

Fig. 35. Cross section comparison of the $4 p(2)$ and $5 p(0)$ spectra for ${ }^{12} \mathrm{C}^{16} \mathrm{O}$ (upper, E12) and ${ }^{13} \mathrm{C}^{16} \mathrm{O}$ (lower), at the same wavelength scale. The possible origin of the perturbations observed in ${ }^{13} \mathrm{C}^{16} \mathrm{O}$ is clearly visible. Experimental spectra are drawn in black, and fits are in color.

to offer even in a well-studied molecule like CO. With the previous publication (E12), our present results provide the most thorough sets of data on these bands for modeling CO isotopologue photochemistry.

Acknowledgements. M.E. and A.H. wish to thank H. Lefèbvre-Brion for stimulating discussions and helpful suggestions. This research was supported by funds from CNRS (France), Programme National Physico-Chimie du Milieu Interstellaire (PCMI) and NASA (grants NNG 06-GG70G and NNX10AD80G to the Univ. of Toledo and NNX09AC5GG to Wellesley College). L.G. and J.L.L. acknowledge the financial support of the European Community 7th Framework Programme (FP7/2007-2013) Marie Curie ITN under grant agreement \# 238258.

\section{References}

de Oliveira, N., Joyeux, D., Phalippou, D., et al. 2009, Rev. Scientific. Instr., 80, 3101

de Oliveira, N., Roudjane, M., Joyeux, D., et al. 2011, Nature Photonics, 5, 149 Eidelsberg, M., Benayoun, J. J., Viala, Y. P., \& Rostas, F. 1991, A\&AS, 90, 231 Eidelsberg, M., Launay, F., Ito, K., et al. 2004a, J. Chem. Phys., 121, 292 Eidelsberg, M., Lemaire, J. L., Fillion, J. H., et al. 2004b, A\&A, 424, 355
Eidelsberg, M., Sheffer, Y., Federman, S. R., et al. 2006, ApJ, 647, 1543 Eidelsberg, M., Lemaire, J. L., Federman, S., et al. 2012, A\&A, 543, 69 (E12) Eikema, K. S. E., Hogervorst, W., \& Ubachs, W. 1994, Chem. Phys., 181, 217

Federman, S. R., Fritts, M., Cheng, S., et al. 2001, ApJS, 134, 133

Gavilan, L., Lemaire, J. L., Eidelsberg, M., et al. 2013, J. Phys. Chem. A, 117, 9644

Herzberg, G. 1950, Molecular spectra and molecular structure, 1: Spectra of diatomic molecules, 2nd edn. (New York: Van Nostrand Reinhold)

Lefèbvre-Brion, H., \& Eidelsberg, M. 2012, J. Mol. Spec., 271, 59

Levelt, P. F., Ubachs, W., \& Hogervorst, W. 1992a, J. Phys. II France, 2, 801

Levelt, P. F., Ubachs, W., \& Hogervorst, W. 1992b, J. Chem. Phys., 97, 7160

Nahon, L., de Oliveira, N., Garcia, G., et al. 2012, J. Synchrotron Radiat., 19, 508

Nahon, L., de Oliveira, N., Garcia, G. A., et al. 2013, J. Phys.: Conf. Ser., 425, 122004

Saloman, E. B. 2004, J. Phys. Chem. Ref. Data, 33, 765

Stark G., Yoshino K., Smith P. L., Ito K., \& Parkinson W. H. 1991, ApJ, 369, 574

Stark, G., Yoshino, K., Smith, P. L., et al. 1993, ApJ, 410, 837

Stark, G., Lewis, B. R., Gibson, S. T., \& England, J. P. 1999, ApJ, 520, 732

Stark, G., Heays, A. N., Lyons, J. R., et al. 2014, ApJ, in press 